\title{
Characterizing the European Sub-Arctic Winter Climate since 1500 Using Ice, Temperature, and Atmospheric Circulation Time Series
}

\author{
Christin ERIKSSON AND ANDERS OMSTEDT \\ Department of Oceanography, Earth Science Centre, Göteborg University, Göteborg, Sweden \\ JAMES E. OVERLAND \\ NOAA/Pacific Marine Environmental Laboratory, Seattle, Washington \\ Donald B. PERCIVAL \\ Applied Physics Laboratory, University of Washington, Seattle, Washington \\ HAROLd O. MOFJELD \\ NOAA/Pacific Marine Environmental Laboratory, Seattle, Washington
}

(Manuscript received 1 May 2006, in final form 21 February 2007)

\begin{abstract}
This study describes winter climate during the last $500 \mathrm{yr}$ for the greater Baltic Sea region through an examination of well-documented time series of ice cover, sea level pressure, and winter surface air temperatures. These time series have been the focus of previous studies, but here their covariation over different time scales is analyzed based on two modern descriptive statistical techniques, matching pursuit and wavelet analysis. Independently, 15 time periods were found during the last $500 \mathrm{yr}$ with different climatic signatures with respect to winter severity, circulation patterns, and interannual variability. The onsets of these periods are presumably caused largely by perturbations within the system, although correspondences with solar and volcanic activity can be identified for certain of the periods. The Baltic region climate has changes on both centennial and decadal time scales, often with rapid transitions. Major warmer periods were the first half of the eighteenth century and the twentieth century. A common feature for warm (cold) periods is low (high) variability on shorter time scales. Century-scale variability and the modulation of interannual and decadal signals are quite diverse in the temporal records and do not suggest strong periodicities. An "event" type conceptual model therefore appears adequate for characterizing Baltic climate variability.
\end{abstract}

\section{Introduction}

The Baltic Sea climate varies greatly in many parameters, including river runoff, salinity, sea level, and sea ice extent. The main reason for this is the location of the Baltic Sea between the North Atlantic and Eurasian air masses, a location that leads to large seasonal and interannual variation in low- and high-pressure systems. The variability is greatest for the winter since solar radiation is weak and atmospheric circulation is

Corresponding author address: Christin Eriksson, Department of Oceanography, Earth Science Centre, Göteborg University, Box 460, SE-405 30 Göteborg, Sweden.

E-mail: chpe@oce.gu.se strong. The twentieth century experienced many mild winters which to a large extent are a result of an increased frequency of westerly winds (Omstedt et al. 2004). Ice in the Baltic Sea is an excellent indicator of winter conditions, and several studies identified the close link between atmospheric circulation and ice conditions (Koslowski and Glaser 1995; Tinz 1998; Jevrejeva and Moore 2001; Omstedt and Chen 2001; Bergström and Ekman 2002; Chen and Li 2004; Omstedt et al. 2004). The future evolution of Baltic Sea ice is of concern, as it is expected that even small climatic changes will be represented in ice impacts (Haapala et al. 2001; Jevrejeva et al. 2004; Omstedt and Hansson 2006a,b).

Although the approach and interpretations of previ-

DOI: 10.1175/2007JCLI1461.1 
ous authors may differ, they do suggest trends, regime shifts, and oscillations for the three main time series that we will investigate. For example, in the surface air temperature series for Uppsala, Sweden, a small positive trend is present, resulting in higher temperatures in the latter portion of the record (Bergström and Moberg 2002). Similarly, negative trends indicating a reduction in ice formation are found in the maximal annual ice cover extent (MIB) and in the western Baltic ice severity index (Seinä and Palosuo 1996; Koslowski and Glaser 1999). It has also been shown that the MIB experienced a regime shift in 1877 (Omstedt and Chen 2001), and that temperatures in Uppsala decreased after 1745 (Bergström and Moberg 2002). Likewise, the ice winter severity in the western Baltic (IWB) has been constant since 1860 (Koslowski and Glaser 1999). Previous investigations have identified oscillations over scales of $2.2-3.5,5.7-7.8$, and $12.8 \mathrm{yr}$. These oscillations are typically associated with large-scale circulation patterns, such as the Arctic Oscillation (AO) and the North Atlantic Oscillation (NAO), which have a 2-8 yr periodicity (e.g., Appenzeller et al. 1998). Correlations of climatic variables with the NAO are highest during the wintertime and are found in both temperature (Chen and Hellström 1999) and Baltic Sea ice conditions (Omstedt and Chen 2001; Jevrejeva and Moore 2001; Jevrejeva et al. 2003). The correlations between the Baltic Sea winter climate and NAO have shown to be unstable and vary with time, where the highest correlations are found during the twentieth century (Chen and Hellström 1999; Omstedt and Chen 2001). Characterizations of Baltic winter seasons during the last $500 \mathrm{yr}$ have been made in different ways. Koslowski and Glaser (1999) use the IWB to define weak and strong phases, Jevrejeva (2001) relates the Riga, Latvia, ice breakup dates to the MIB to classify the Baltic winter seasons, and a Baltic winter index (WIBIX) was created by Hagen and Feistel (2005).

The data under study span 1500-2000, a period including the warm twentieth century and the Little Ice Age (LIA), which occurred from roughly the early sixteenth century through the late nineteenth century (see, for instance, Ogilvie and Jónsson 2001 for a discussion regarding the definition). However, conditions in the LIA were far from temporally uniform. How the climate varied during the LIA has been addressed in several studies (e.g., Lamb 1995; Fagan 2000), and is described both as a generally cold period and as the most recent period during which the glaciers advanced from time to time (Grove 2001; Nesje and Dahl 2003). Recent reconstructions of Northern Hemisphere temperatures indicate that the LIA was a widespread climatic phenomenon (e.g., Moberg et al. 2005), yet this period is still little understood. Based on model studies, preindustrial decadal and longer-term regional climate changes have been suggested to be driven by solar variability, due to forced AO-NAO shifts as dynamics and radiation working together (Shindell et al. 2003). The climatic and circulation changes over the past $500 \mathrm{yr}$ have also been modeled with a coupled atmosphereocean model driven by solar variability, volcanic activity, and atmospheric concentrations of greenhouse gases, and have shown good correlation with tree-ringbased reconstructions (Zorita et al. 2004).

Two statistical methods, matching pursuit and wavelet analysis, are applied to analyze several ice and temperature time series for the past $500 \mathrm{yr}$. Results support the linkage of climatic parameters of ice, air temperature, and atmospheric circulation over the greater Baltic region. Matching pursuit provides a method to determine what types of temporal patterns are characteristic, while wavelet analysis suggests their variability. By decomposing the pressure field in directional and rotational components this study provides improved representations of circulation changes compared to single circulation indices such as the NAO. This study is also intended to form a base for Baltic Sea model development and validation.

The winter climate for the last $500 \mathrm{yr}$ includes both the preindustrial era and the human-influenced past 150 yr. Knowledge about the natural variability is essential for detection and attribution of climate change over the area and is currently lacking for the Baltic Sea. In section 2 we describe the data sources used and how the gridded sea level pressure (SLP) dataset was converted to circulation indices and mean temperatures, which is further explained in appendix A. Section 3 briefly describes the statistical methods, and this description continues in appendices B and C. Section 4 presents the results of the statistical analysis and defines 15 climate periods. In section 5 these periods and their relationships to the circulation and temperature data are discussed. Conclusions are in section 6 .

\section{Data sources and circulation indices}

Our study uses data describing sea ice, surface air temperature, and sea level pressure (Table 1; Figs. 1 and 2) representative of winter conditions over the greater Baltic region, here defined as the Baltic Sea and the land close to its shores. The winter season is most often associated with December, January, and February (DJF), the period during which most ice growth occurs. The reasons for using winter data are twofold. First, in the sub-Arctic, the largest year-to-year variability in climate occurs in winter. Second, recon- 
TABle 1 . Time series $(a-h)$ and gridded data ( $i$ and $j)$ used in this study together with main references. The term d.y. represents day of year.

\begin{tabular}{|c|c|c|c|c|c|}
\hline No. & Climate variable & Region & Time span & Resolution & Main reference \\
\hline $\mathrm{a}$ & Air temperature $\left({ }^{\circ} \mathrm{C}\right)$ & Uppsala & $1722-1998$ & Monthly & Bergström and Moberg (2002) \\
\hline $\mathrm{b}$ & $\operatorname{MIB}\left(10^{3} \mathrm{~km}^{2}\right)$ & Baltic Sea & $1720-2002$ & Annual & Seinä and Palosuo (1996) \\
\hline c & IWB (index) & Baltic Sea & 1500-1999 & Annual & Koslowski and Glaser (1999) \\
\hline d & Ice breakup (d.y.) & Mälaren & $1712-1997$ & Annual & Eklund (1999) \\
\hline $\mathrm{e}$ & Ice breakup (d.y.) & Torneå & $1693-2002$ & Annual & Kajander (1993) \\
\hline $\mathrm{f}$ & Ice breakup (d.y.) & Riga & 1529-1988 & Annual & Jevrejeva (2001) \\
\hline $\mathrm{g}$ & Ice breakup (d.y.) & Tallinn & $1500-2000$ & Annual & Tarand and Nordli (2001) \\
\hline $\mathrm{h}$ & Winter air temperature $\left({ }^{\circ} \mathrm{C}\right)$ & Tallinn & $1500-2000$ & Annual & Tarand and Nordli (2001) \\
\hline $\mathrm{i}$ & Sea level pressure $(\mathrm{hPa})$ & Northern Europe & $1500-1995$ & Seasonal & Luterbacher et al. (2002) \\
\hline $\mathrm{j}$ & Air temperature $\left({ }^{\circ} \mathrm{C}\right)$ & Northern Europe & $1500-2002$ & Seasonal & Luterbacher et al. (2004) \\
\hline
\end{tabular}

structed sea level pressure data are most accurate for the winter (Luterbacher et al. 2002). Our main series are the DJF air temperatures in Uppsala, MIB, and IWB (Figs. 2a-c; Table 1). These series are well documented and have been used previously in other studies; they are also some of the longest historical climatological records in existence. The other series-ice breakup in Mälaren, Sweden; Torneå, Finland; Riga, Latvia; and Tallinn, Estonia (Figs. 2d-g; Table 1); winter air temperature in Tallinn (Fig. 2h; Table 1); and SLP and winter air temperature for Northern Europe (gridded data, not shown but references are given in Table 1) are used to confirm and support our main results and are not described as completely as the main series. Although ice breakup is a spring phenomenon usually occurring during March-May, these data are used in the study because some authors suggest a link between ice breakup and winter severity (e.g., Jevrejeva 2001).

Surface air temperature records from Uppsala date

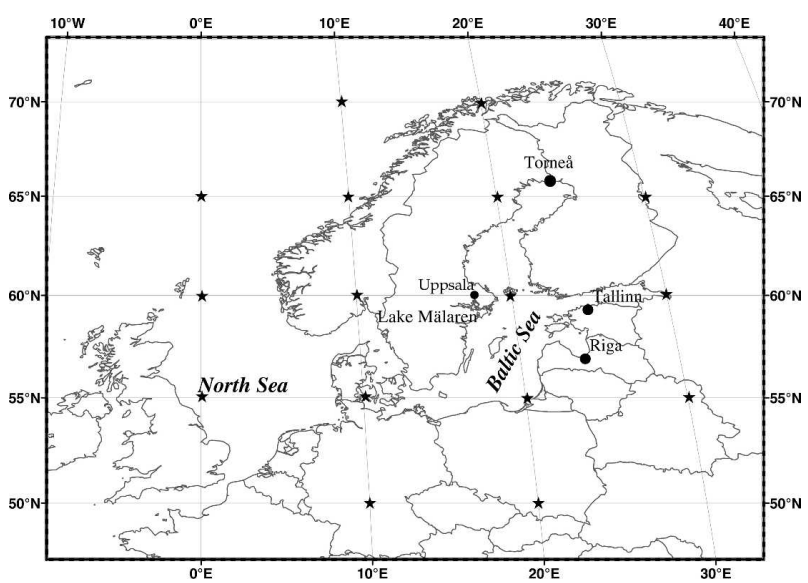

FIG. 1. The Baltic Sea and Skagerrak system. Locations of the ice breakup series are indicated with dots. Stars indicate the pressure points used when calculating the atmospheric circulation indices. from 1722. The temperature series has been compiled, quality controlled, and homogenized by Bergström and Moberg (2002). Unfortunately, the early part of the series was disrupted by relocation of the thermometers
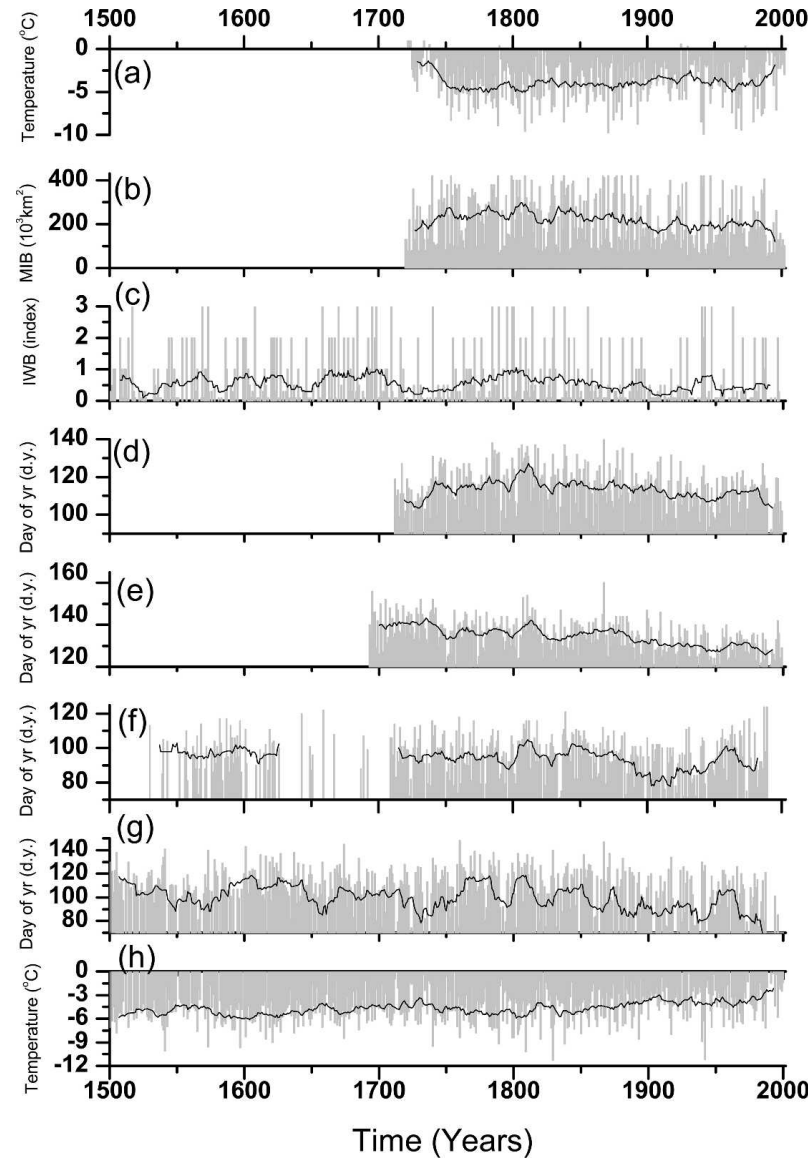

FIG. 2. Time series used in the analysis: (a) Uppsala winter air temperature, (b) maximum annual ice cover extent in the Baltic $\mathrm{Sea}$, (c) ice winter severity in the western Baltic. Date of ice breakup in (d) Lake Mälaren, (e) Torneå River, (f) port of Riga, and $(\mathrm{g})$ port of Tallinn. (h) Winter air temperature in Tallinn. 
to regrettably ill-ventilated locations. However, the mean DJF temperature data were subjected by the authors to a correlation analysis with precipitation, and can be regarded as accurate.

The MIB series describes the ice-covered area of the Baltic Sea from the Bothnian Bay to the Skagerrak strait starting in 1720 . The data are summarized and described in Seinä and Palosuo (1996). The first part of the time series, covering $1720-1940$, was originally summarized by R. Jurva and is drawn from various sources, such as observations at lighthouses, old newspapers, and records of travel on the ice. Unfortunately, Jurva never published the whole time series, and his last publication only covered the years from 1830 onward (Jurva 1952). The time series figures were published in Palosuo (1953), from which the ice extent was later digitized by various authors (Alenius and Makkonen 1981; Leppäranta and Seinä 1985; Lamb 1995). The data that are most commonly used (Seinä and Palosuo 1996, their appendices 1 and 2) consist of the estimated maximum ice extents for the winters prior to 1830 , taken from the original figures, where the data are presented with an estimate of uncertainty. The greatest uncertainties are found during severe winters, such as that of $1739-40$, with ranges as great as $15 \%-20 \%$ $\left(70000 \mathrm{~km}^{2}\right)$. However, owing to the high correlation between air temperature, at both Stockholm and Helsinki, and ice extent (Seinä and Palosuo 1996; Tinz 1998), the data can be regarded as reasonably accurate. The latter part of the time series, covering 1941-1995, is based on data from the Finnish operational ice service. Omstedt and Chen (2001) also showed that there is a good correlation between this series and the winter NAO index, and that the decreasing trend in the time series can be explained by a regime shift in 1877, probably caused by a change in atmospheric circulation (Omstedt et al. 2004). The 1877 regime shift is regarded as the end of the LIA in the Baltic region, and was identified by a "change point" analysis in Omstedt and Chen (2001).

The IWB series describes the severity of the southwestern Baltic Sea ice winters starting in 1501 and is constructed from historical ice data from places close to the Baltic entrance (Koslowski and Glaser 1995, 1999). The main sources are documents from German and Danish ports and lighthouses, which, together with ship passage frequencies, are considered to represent early ice conditions.

Bergström and Ekman (2002) point out that from 1720 to 1770 both the MIB and the IWB series come from the same source, namely, Speerschneider (1915). Even though these series reference the same data, both series were chosen to be analyzed because they are based on independent sources outside of the 1720-1770 period, which is short compared to the total extent of the two series.

Dates of ice breakup in Lake Mälaren have been analyzed by Eklund (1999). This series dates from 1712 and displays a good correlation with the Uppsala air temperature from February to April. Dates of ice breakup in the Torneå River were compiled by Kajander (1993) in a series dating from 1693; this time series mainly reflects the April and May temperature. Ice winter severity has been reconstructed from data capturing ice breakup at the port of Riga from 1529 to 1988 (Jevrejeva 2001). There are some gaps for the period before 1708, after which the annual data are continuous. For Tallinn two time series are used describing ice breakup and winter air temperatures during 1500-2000. In most cases, the date of ice breakup is usually the day for the arrival of the first ship in spring. Air temperature series consists of temperature observations from 1757 and onward, while the earlier part of the series is a proxy-based time series constructed from dates of ice breakup for the port of Tallinn (Tarand and Nordli 2001).

Two gridded datasets were also used. The first consists of sea level pressure reconstructions with a resolution of $1^{\circ} \times 1^{\circ}$ from $30^{\circ}$ to $70^{\circ} \mathrm{N}$ and $30^{\circ} \mathrm{W}$ to $40^{\circ} \mathrm{E}$. This is an updated version of the $5^{\circ} \times 5^{\circ}$ dataset by Luterbacher et al. (2002) for 1500-1995, with monthly data back to 1659 and seasonally before. Only DJF means were used and circulation indices were calculated over the Baltic Sea region by using the grid shown as stars in Fig. 1. The second gridded dataset consists of the surface air temperature from Luterbacher et al. (2004) and Xoplaki et al. (2005). The latter has a resolution of $0.5^{\circ} \times 0.5^{\circ}$ from $30^{\circ}$ to $70^{\circ} \mathrm{N}$ and $25^{\circ} \mathrm{W}$ to $40^{\circ} \mathrm{E}$ for 1500-1995 with monthly data back to 1659 and seasonally before. The reconstructed data were based on multiproxy reconstructed data on a seasonal scale beginning in 1500. It should be noted that the reconstructed temperatures from 1500 to 1900 were based on temperature predictors, and thus do not include any station pressure series. Again only the DJF means were used from the dataset to characterize the winter climatic conditions. A horizontal mean of the Baltic Sea winter air temperature was constructed by averaging data from 13 grid points at the Baltic Sea coast, since no data were available over open water.

In analyzing the atmospheric circulation, circulation indices were calculated based on seasonal winter sea level pressure data from Luterbacher et al. (2002). The geostrophic velocity field $\mathbf{V}$ was decomposed via a Tay- 
lor series expansion into five basic flow fields (see appendix A):

$$
\mathbf{V}=\mathbf{V}_{0}+\mathbf{R}+\mathbf{E}+\mathbf{D}_{1}+\mathbf{D}_{2}
$$

The first term, $\mathbf{V}_{0}$, represents zonal and meridional winds. The second term, $\mathbf{R}$, is a rotational component and hence the strength of the circular movement of air masses. Positive values are associated with cyclonic rotation (low-pressure systems) and negative values with anticyclonic circulation (high-pressure systems). The third term, E, represents convergence or divergence. The two deformation velocity fields represent the torque put on the velocity field due to shear, $\mathbf{D}_{1}$, and normal deformation, $\mathbf{D}_{2}$. Based on pressure data from the 16 points shown as stars in Fig. 1, the flow fields were calculated as indices, as in Chen (2000).

\section{Approach: Matching pursuit and wavelets}

Tow statistical methods were used to analyze the variability of our time series. The matching pursuit (MP) technique in combination with a complementary wavelet analysis provides a powerful method for examining time series (Percival et al. 2004). By using air temperature and atmospheric circulation indices to explain temporal features selected by MP, we have been able to identify climate events that differ from each other during the period under study.

As discussed in Percival and Walden (2000) and Percival et al. (2004), the idea underlying MP is to approximate a time series in terms of a small number of vectors selected from a large collection of vectors called a dictionary. The efficacy of the approximation depends critically on the contents of the dictionary. As originally formulated by Mallat and Zhang (1993), the dictionary contained vectors that allowed the time/ frequency decomposition of a time series. Figure 3 shows the different types of vectors associated with our dictionary. The dictionary allows selection of episodic events, along with sinusoidal and square wave oscillations. Episodic events are handled by a sequential vector of the same sign and by a Haar wavelet shape, which is a vector with adjacent values of opposite sign. We also included square wave oscillations because of our interest in describing climate variability in terms of sudden regime-like shifts. With the dictionary so defined, MP is useful for picking out abrupt changes or events in climate time series. Details of the method are provided as appendix B.

MP provides an additive decomposition of a time series and guarantees a decrease in the sum of squares of the residuals at each successive step of the sequential (a)

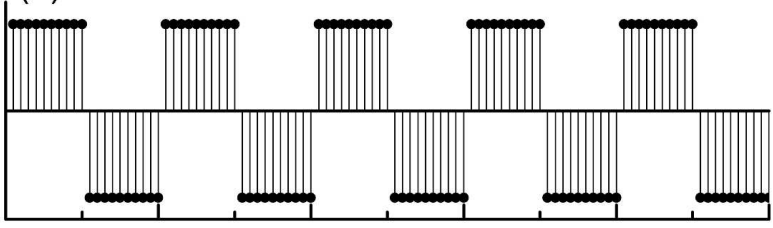

(b)

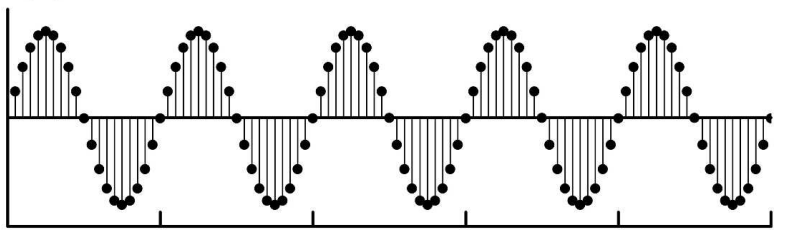

(c)

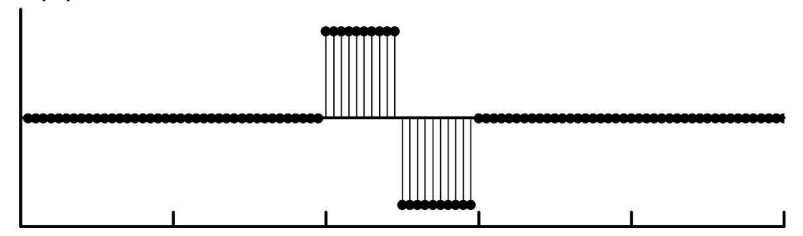

(d)

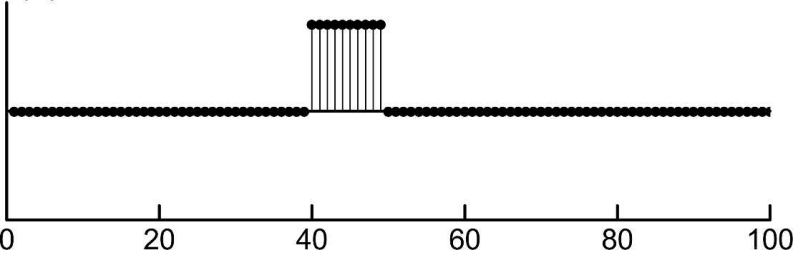

FIG. 3. Examples of dictionary elements used in matching pursuits analyses of time series. (a) A vector containing a square wave oscillation with a period of 20 time steps in the time series. (b) A vector containing a sinusoidal oscillation, also with a period of 20 . (c) A vector created from a discretized Haar wavelet function associated with changes on a scale of 10 . (d) A vector that describes a grouping of 10 .

fitting of a time series. By successively comparing the residuals at a given step to the vectors in the dictionary, we build up a picture of what constitutes the important components of a time series. MP is a valuable tool for exploratory data analysis because it provides an objective method of exploring a time series in terms of a collection of possible explanatory patterns, both periodic and episodic. In addition, some of the first vectors picked out by MP might also serve as the starting points of more formal statistical models. The periods singled out in the MP analysis can be further examined by using wavelet analysis.

Wavelet analysis is a useful method for analyzing climate time series (Percival et al. 2004) and complements our use of matching pursuit. The continuous wavelet transform (CWT) of time series $x$ with respect to wavelet $\psi$ is defined as 


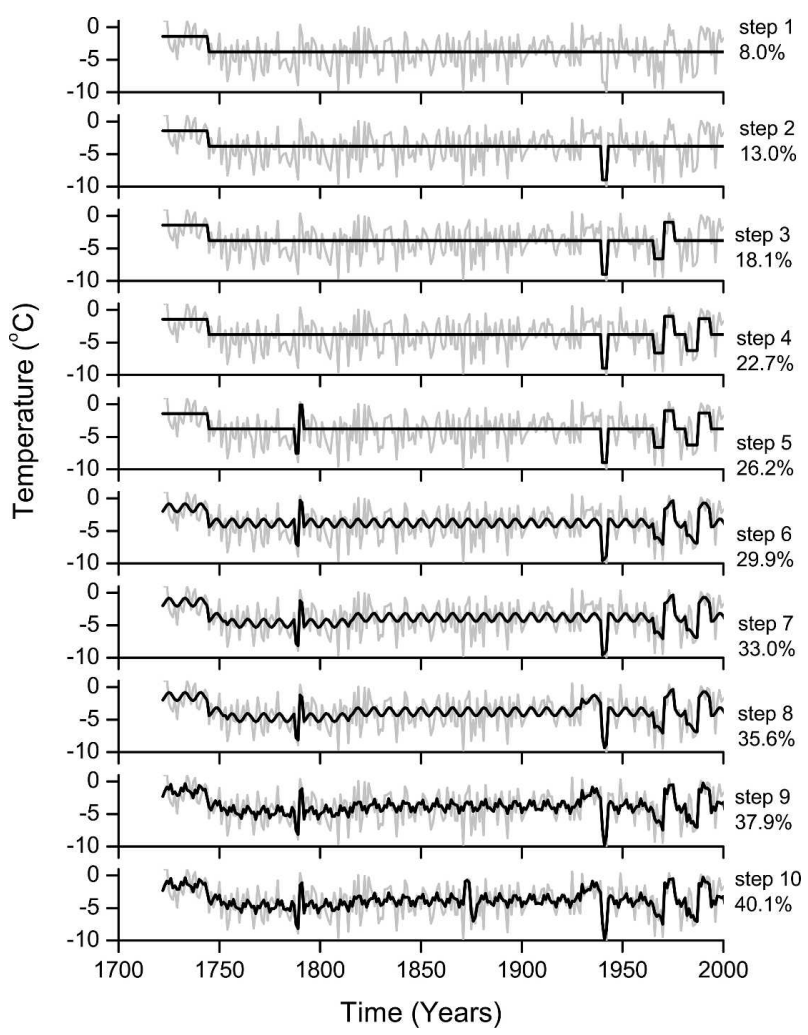

FIG. 4. Matching pursuit analysis of Uppsala winter air temperature. Top panel shows the first event (black line) picked out by the matching pursuit analysis, together with the original time series (gray line). The succeeding panels show the results of the next steps as black lines. At each step, the percentage of the explained total variance is indicated.

$$
W(\lambda, t) \equiv \int_{-\infty}^{\infty} \psi_{\lambda, t}(u) x(u) d u
$$

where

$$
\psi_{\lambda, t}(u)=\frac{1}{\sqrt{\lambda}} \psi\left(\frac{u-t}{\lambda}\right) .
$$

The variable $\lambda$ is the scale and $t$ is the point where the wavelet is centered.

In practical applications the CWT cannot be computed exactly, because $x$ is only recorded at selected times. So in place of the CWT we use the discrete wavelet transform (DWT), which is specifically designed to work with time series sampled at equal intervals (irregular sampling is typically handled by interpolating the data). The DWT can be regarded as an approximation of the CWT over a so-called dyadic grid of scales. Each row is usually set to the largest integer that is less than or equal to $\log _{2}(N) ; N$ represents the sample size.

The DWT also requires the discretization of the continuous time variable. In this study we used the maximal overlap DWT (MODWT), which gives $N$ wavelet

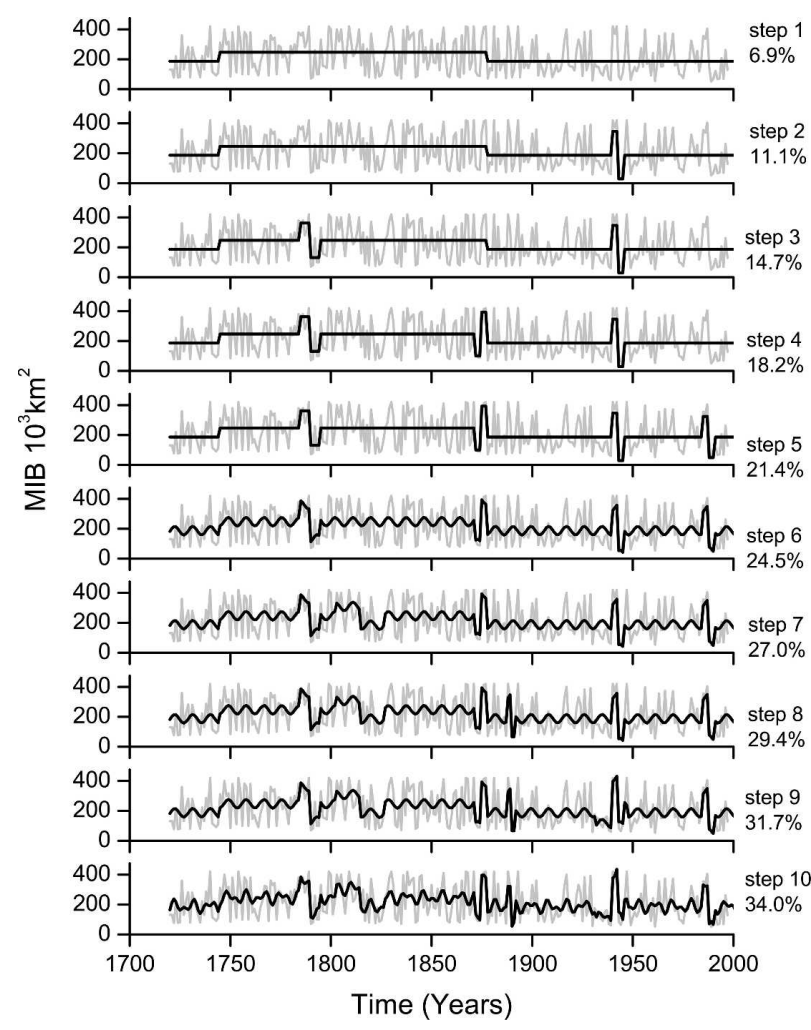

FIG. 5. As in Fig. 4, but for MIB.

coefficients for each dyadic scale. Additional details are provided in appendix $\mathrm{C}$.

\section{Results}

\section{a. Matching pursuit}

In Figs. 4-6 we show the results of the MP analysis. Each of the time series was subject to MP analysis after it had been centered by subtracting its sample mean. After each step of the MP analysis, the approximation time series, $\mathbf{X}^{(m)}$, was then plotted from top to bottom in each figure. At each step we calculated the percentage of the variance explained, by taking $\left(\|\mathbf{X}\|^{2}-\right.$ $\left.\left\|\mathbf{R}^{(m)}\right\|^{2}\right) /\|\mathbf{X}\|^{2} \times 100 \%$, where $\mathbf{R}^{(m)}$ is the residual vector.

The Uppsala winter surface air temperature record is shown in Fig. 4. The most pronounced feature of this series is the warm period, shown as an event in the early part in the eighteenth century (1722-44), which accounts for $8 \%$ of the total variance. The next step describes a grouping of cold winters in the early 1940s (1940-42). After these two steps, $13 \%$ of the total variance has been explained. The third, fourth, and fifth steps pick out the Haar wavelet shape for 1966-75, 1982-93, and 1788-91, and these events explain $26.2 \%$ 


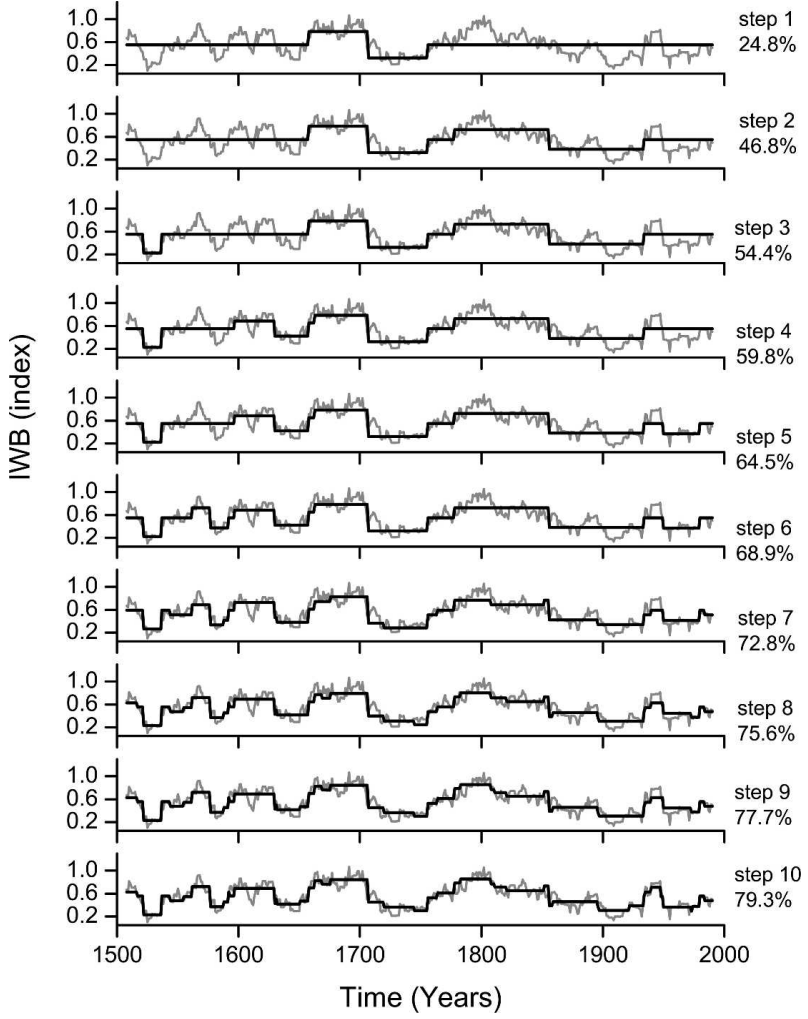

FIG. 6. As in Fig. 4, but for IWB.

of the total variance. In steps 6-9, MP picks out both sinusoidal oscillations and events (7.8 yr, 1754-1814, 1930-40, and $2.4 \mathrm{yr}$ ). In the tenth step, another Haar wavelet is picked out (1872-77); and the total explained variance after this last step is $40.1 \%$.

In Fig. 5 we show the MP analysis of the MIB. The first feature is characterized by a square wave with a period of $266 \mathrm{yr}$, the positive portion of its oscillation extending from 1745 to 1877 . This corresponds to a long period of relatively cold winters since the latter half of the eighteenth century, which ended in what is also known as the breakdown of the LIA (Omstedt and Chen 2001). This first event accounts for $6.9 \%$ of the total variance. The second feature is a cold winter event in the early 1940s, visible as a Haar wavelet (1940-45), which together with the first step explains $11.1 \%$ of the total variance. The next three steps are Haar multiannual events (1785-94, 1872-77, and 1985-90), and after this fifth step $21.4 \%$ of the total variance has been explained. Steps 7, 8, and 9 are Haar events (1803-26, 1888-91, and 1932-47). At steps 6 and 10, MP picks out sinusoidal oscillations with periods of 8.8 and $5.2 \mathrm{yr}$. After the tenth step $34 \%$ of the total variance has been explained.

Results for the IWB are shown in Fig. 6. A 15-yr running mean was applied to the series before the MP analysis. This preprocessing was necessary because IWB by definition only assumes 7 discrete values ( 0 , $0.1,0.3,0.5,1,2$, and 3). As a result, the MP method picks out small groupings of the largest values rather than the multiyear patterns of interest here. Use of the running mean overcomes this difficulty. The first event occurs near the Late Maunder Minimum (LMM) at the transition between the seventeenth and eighteenth centuries (Luterbacher et al. 2001). This event is characterized as a Haar wavelet (1658-1755) and accounts for $24.8 \%$ of the total variance. In the second step, the ending of the LIA is pictured as the transition between the warm and cold part of the Haar wavelet (17781933); and the explained total variance is now $46.8 \%$. In steps 3,5, and 9, decadal and longer groups are selected (1522-36, 1950-79, and 1651-1810), while in steps 4, 6, and 10, Haar wavelets are selected (1597-1662, 156291, and 1922-73). Low-frequency square wave oscillations are picked out in steps 7 and 8 (88- and 76-yr periods, respectively). After the tenth and last step, MP has explained $79.3 \%$ of the total variance of the smoothed series.

The most interesting part of the MP analysis is the placement of the time periods picked out. For the temperature series the positive parts of the dictionary vectors chosen by the MP method describe a milder-thanaverage climate compared to the overall mean, while the negative parts describe a colder-than-average climate. For the IWB, MIB, and ice breakup series, the positive parts describe a colder-than-average climate, and negative parts describe a milder-than-average climate. Figures 7 and 8 synthesize the results of the MP analysis in an accessible format, showing the longest and shorter periods, respectively, selected for the three main and five secondary series. All small-scale oscillations of the type shown in Figs. 3a,b were omitted when plotting Fig. 8 since the focus is on events not associated with oscillations (these are treated separately in the wavelet analysis described in section $4 \mathrm{~b}$ ). Blue fields represents a colder-than-average climate, compared to the overall mean of the time series, the opposite being the case with the red fields. Black fields indicate no data and white fields are years not flagged by the MP analysis. Several mild and cold periods are evident, often co-occurring in more than one of the series. The exact definition of the start/end points of an MP period is set to be the best fit of the events found in the MP analysis., Fifteen time periods (MP1-MP15) have been isolated from Figs. 7 and 8; these are presented in Table 2.

Figures 7 and 8 show the climate over the last $500 \mathrm{yr}$ as deduced by the MP analysis. Information about the earliest climate events in the first two centuries comes from the IWB (Fig. 8, column c), and these are listed in 


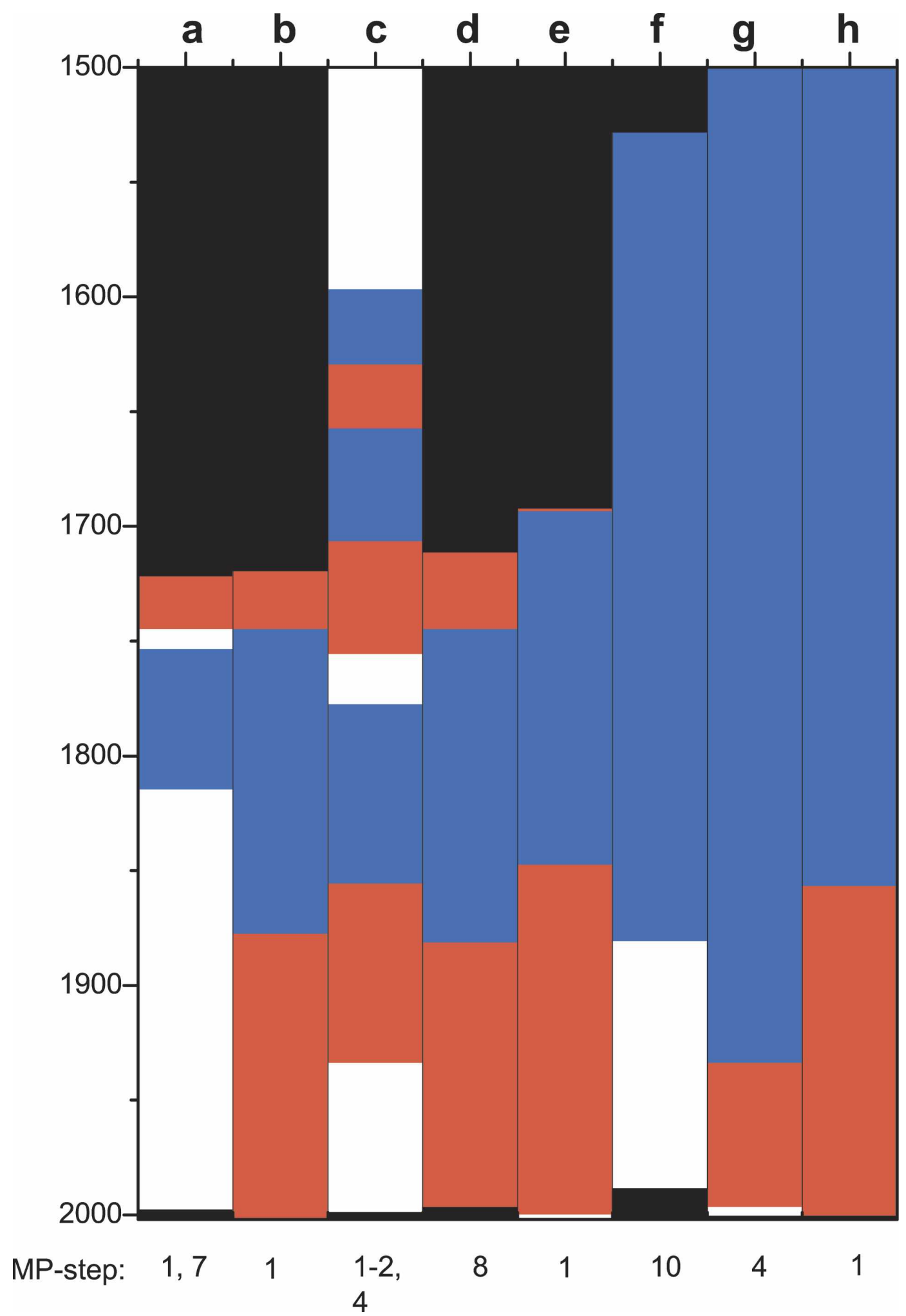

FIG. 7. Results of the matching pursuit analysis for all of the time series. For each time series listed in Table 1 columns $\mathrm{a}-\mathrm{h}$, all the longest periods picked out by the MP analyses are shown here together with the corresponding step. Blue fields represent a colder-than-average climate, compared to the overall mean of the time series, the opposite being the case with the red fields. Black fields indicate no data and white fields are years not flagged by the MP analyses. (a) Mean winter air temperature, Uppsala; (b) MIB; (c) IWB; ice breakups for (d) Lake Mälaren, (e) Torneå River, (f) port of Riga and (g) port of Tallinn; and (h) mean winter air temperature, Tallinn. 


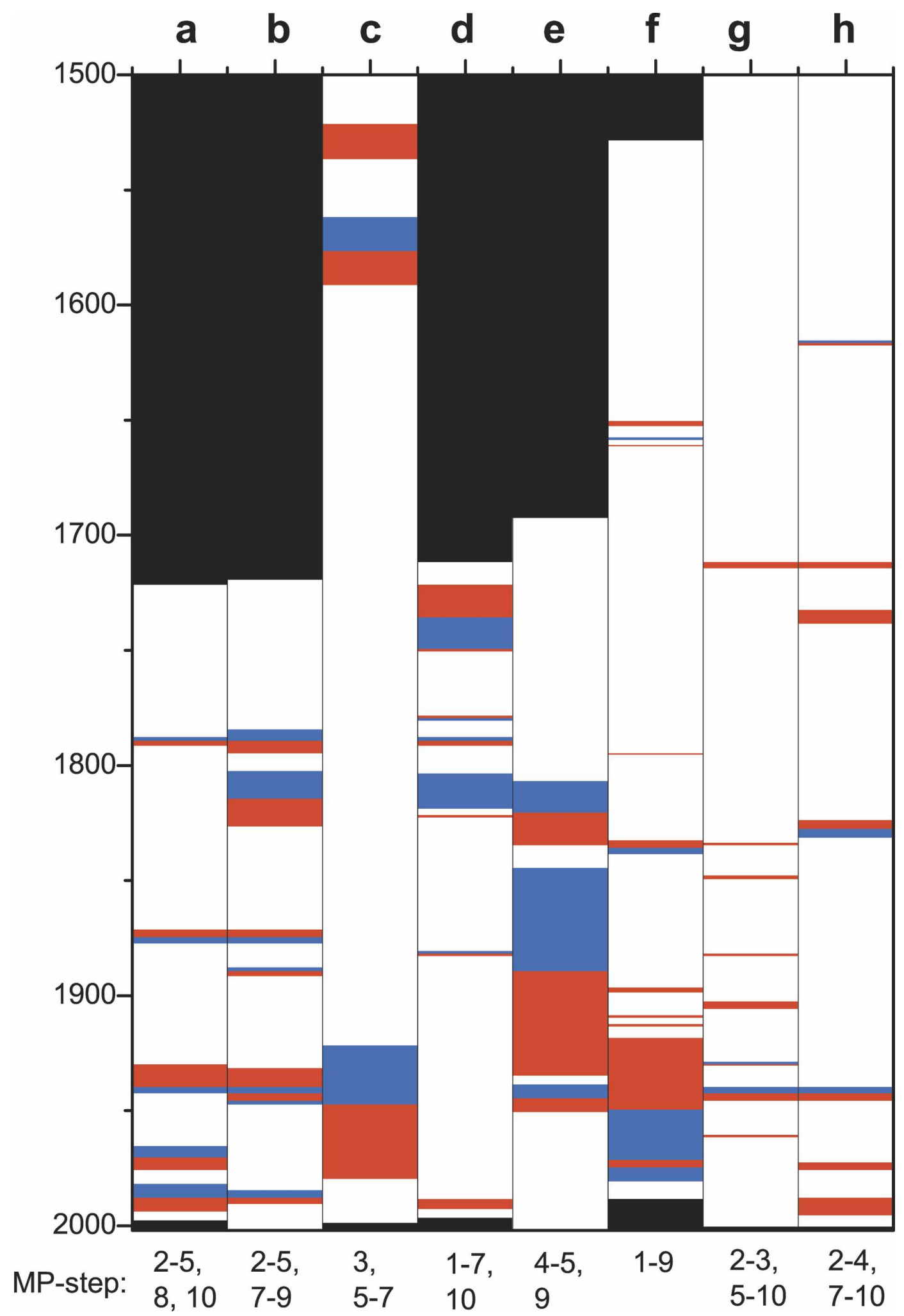

FIG. 8. As in Fig. 7, but instead for the shorter periods picked out by the MP analyses. 
TABLE 2. Periods identified from the MP analysis. Bold font indicates periods warmer than average. Columns a-h refer to the time series listed in Table 1, and the numbers in these columns represent the mean of each time series over the indicated period.

\begin{tabular}{lccccccccc}
\hline \hline No. & Period & $\mathrm{a}\left({ }^{\circ} \mathrm{C}\right)$ & $\mathrm{b}\left(10^{3} \mathrm{~km}^{2}\right)$ & $\mathrm{c}($ index $)$ & $\mathrm{d}($ d.y. $)$ & $\mathrm{e}($ d.y. $)$ & $\mathrm{f}($ d.y. $)$ & $\mathrm{g}(\mathrm{d} . \mathrm{y})$. & $\mathrm{h}\left({ }^{\circ} \mathrm{C}\right)$ \\
\hline MP 1 & $1522-36$ & - & - & 0.25 & - & - & - & 102.71 & -4.81 \\
MP 2 & $1562-76$ & - & - & 0.81 & - & - & $95.4^{*}$ & 90.38 & -4.52 \\
MP 3 & $1577-91$ & - & - & 0.3 & - & - & 97.4 & 106.18 & $-5.69^{*}$ \\
MP 4 & $1597-1629$ & - & - & 0.73 & - & - & 97.4 & 113.65 & -5.84 \\
MP 5 & $1630-62$ & - & - & 0.44 & - & - & 80.25 & 99.73 & -4.72 \\
MP 6 & $1663-1706$ & - & - & 0.85 & - & 140 & 100.5 & 103.18 & -4.77 \\
MP 7 & $1707-50$ & -1.89 & 194.48 & 0.35 & 110.08 & 140.23 & 96.43 & 94.20 & -4.39 \\
MP 8 & $1750-1877$ & -4.38 & 245.51 & 0.64 & 116.39 & 136.21 & 96.06 & 103.84 & -4.98 \\
MP 9 & $1803-1820$ & -4.74 & 275.5 & 0.72 & 124.5 & 139.61 & 103.44 & 111.89 & -5.47 \\
MP 10 & $1878-2000$ & -3.66 & 190.38 & 0.43 & 110.46 & 130.35 & 89.27 & 82.47 & -3.60 \\
MP 11 & $1930-39$ & -1.83 & 116.9 & 0.04 & 107.66 & 128.1 & 83.2 & 75 & -2.76 \\
MP 12 & $1940-42$ & -8.97 & 403.67 & 2.67 & 120.70 & 135.67 & 103.67 & 126.33 & -8.8 \\
MP 13 & $1971-75$ & -1.23 & 120.8 & 0.08 & 107.13 & 129.2 & 75.2 & 37.2 & -1.48 \\
MP 14 & $1985-87$ & -7.39 & 365.67 & 1.67 & 120.39 & 130.67 & 101.33 & 105 & -5.87 \\
MP 15 & $1988-93$ & -0.69 & 87.67 & 0.02 & 90.50 & 123.67 & 111 & 0 & -0.47 \\
Mean & All yrs & -3.79 & 215.04 & 0.55 & 113.03 & 134.63 & 93.80 & 97.73 & -4.63 \\
\hline
\end{tabular}

* The time series have missing values during the period.

Table 2 as events MP1-MP3, followed by MP4-MP6 also from IWB (Fig. 7, column c). Events MP1-MP6 are in good agreement with the periods presented by Koslowski and Glaser (1999). During this time the Riga and Tallinn series were in a cool phase, yet sometimes interrupted by short events that fit in the MP periods. A common feature during the eighteenth century is the warm period around 1730 (MP7), which is picked out in six of the eight time series (Figs. 7 and 8). Lake Mälaren is the only ice breakup series indicating a long warm period around 1730, but the two Tallinn series show shorter warming events during MP7 (Fig. 8). For the Riga series, the lack of a warming event could be due to the fact that the dates of ice breakup are affected by factors other than winter temperatures or that the signal is too weak to be picked out by MP. The ice breakup in Torneå is located so far to the north that it might only partly be affected by circulation changes, which mostly are confined to the southern part of the Baltic Sea region (Bergström and Ekman 2002). There is agreement among all the series that the late eighteenth through late nineteenth centuries was a relatively cold period (MP8). Within the long MP8 event is a short cold time period (MP9) that is evident in three of the time series in the beginning of the nineteenth century (Fig. 8, columns b, d, and e). The ending of the LIA in the late nineteenth century is obvious (Fig. 7, columns b-h), and it occurs at more or less the same time in most of the time series. The last century (MP10) stands out as warm.

Shorter periods with different characteristics are also picked out for the last century, with the warm 1930s event (MP11) as one of the features that appears in more than one series. Agreement is also good concerning the cold winters in the early 1940s (MP12) and the cold period in the 1970s (MP13). Finally the two last periods considered are the cold period in the mid-1980s (MP14) and the warm period of the 1990s (MP15). In section 5 air temperatures and atmospheric circulation indices are examined during these $15 \mathrm{MP}$ periods to characterize the European sub-Arctic winter climate.

\section{b. Wavelet analysis}

Here we present the results of the multiresolution analysis (MRA) of the main time series, based on a MODWT using a D(4) wavelet and assuming a reflection boundary condition. Figure 9 presents an analysis of the Uppsala winter temperature record. The $\tilde{D}_{1}$ plot (associated with changes in averages over a 1-yr scale) shows how interannual variability has changed over the centuries. The most pronounced features are the increased variability at the beginning and end of the nineteenth century and the much-damped period in the early twentieth century. In the $\tilde{D}_{2}$ plot we can see that the cold winters of the 1940s are prominent. The $\tilde{D}_{2}$ component is associated with changes in averages over a 2-yr scale. The cold event is seen as a period of enhanced fluctuations, because the series has similar values for groups of two years, but with large differences between adjacent groups. The plot of $\tilde{D}_{4}$ shows marked differences in the variability of 8 -yr averages across the three centuries. The eighteenth and twentieth centuries appear to be much more similar to each other, with more decadal variability, than to the intervening nineteenth century. The smoothed series, $\tilde{S}_{5}$, is associated with changes on all scales greater than $16 \mathrm{yr}$ and shows the 


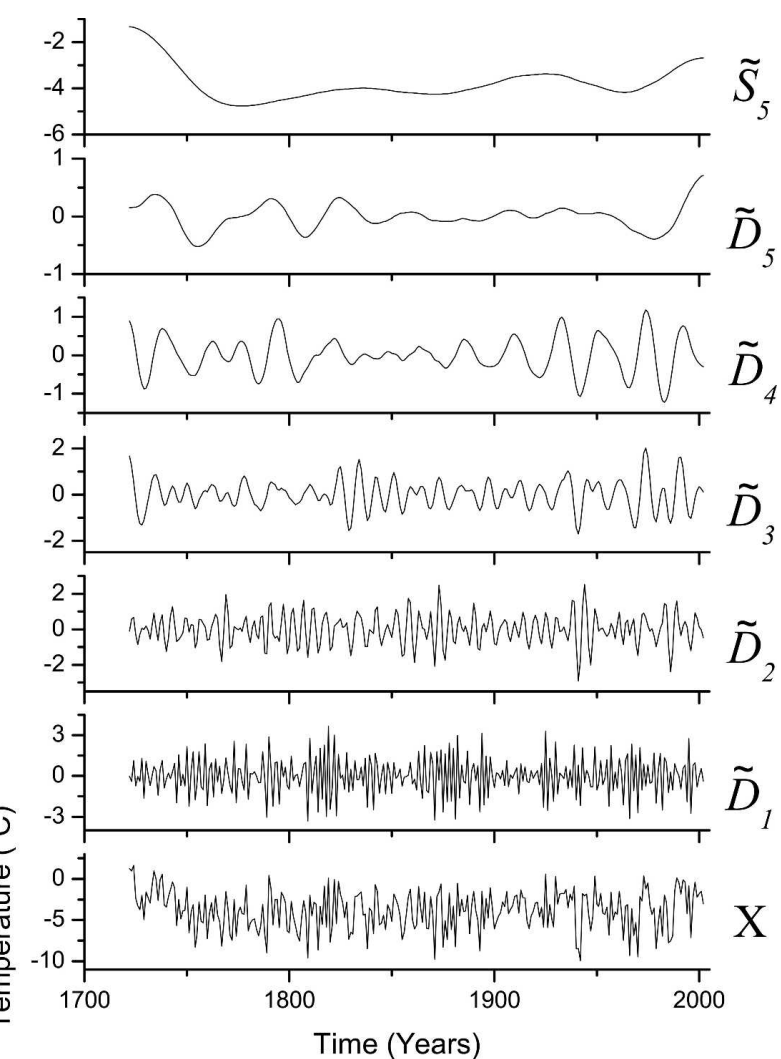

FIG. 9. MRA of Uppsala mean winter air temperatures based upon a maximal overlap discrete wavelet transform using a $\mathrm{D}(4)$ wavelet with reflection boundary conditions. The bottom panel shows the original time series, above which are the $j$ th detail series $\tilde{D}_{j}$ and the smooth series $\tilde{S}_{5}$. The $j$ th detail series is based upon wavelet coefficients that reflect changes in averages over a scale of $2^{j-1}$ years, while the smooth series is associated with changes on all scales greater than $16 \mathrm{yr}$.

long-term evolution, with warming at the beginning and end of the time series.

The outcome of the MRA for maximum ice cover is presented in Fig. 10. In the panel showing the $\tilde{D}_{1}$ vector we note the low interannual variability in the early twentieth century, as also occurred in the temperature record. On 2-yr scale averages we find the greatest variability during the nineteenth century, except for the event during the 1940s. This analysis shows that, as in the Uppsala series, variability on the 8-yr scale is much less in the nineteenth century than in the centuries surrounding it. The top panel showing the smoothed series is consistent with the analysis of the Uppsala temperature series.

The results for the 500-yr IWB series, presented in Fig. 11, show that the interannual variability is more or less constant over the centuries, except for periods around 1525 and the first decade of the twentieth century. Moving up to the $\tilde{D}_{2}$ plot, analyzing averages on a

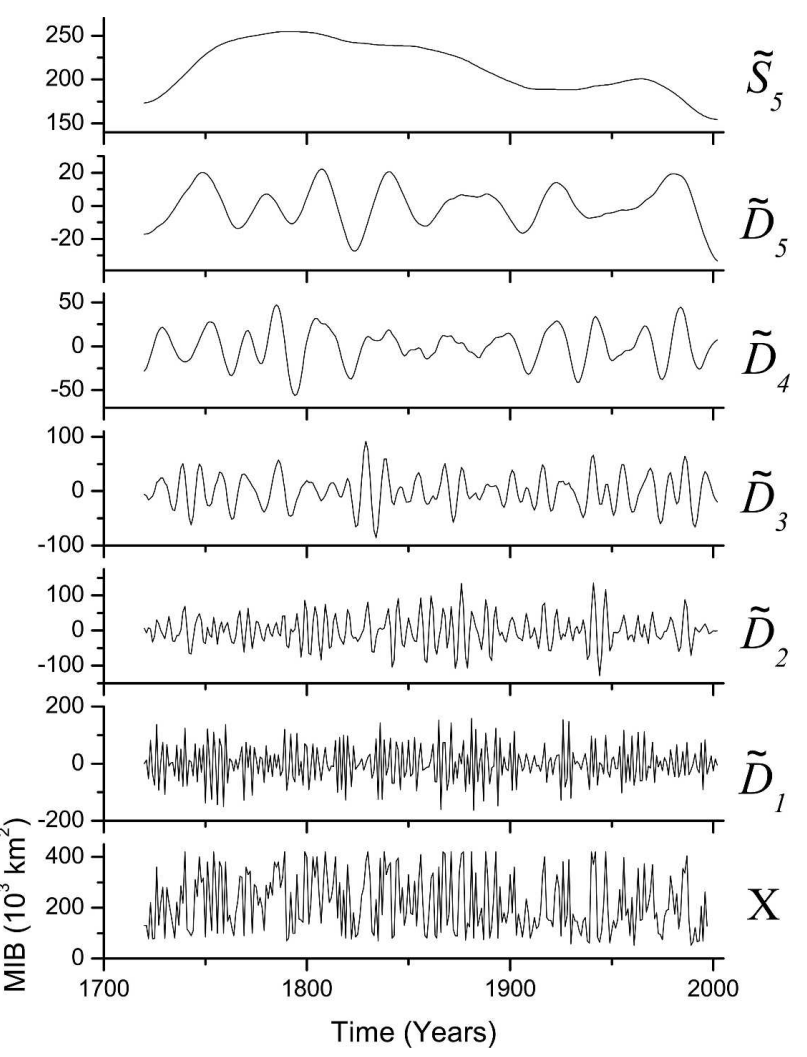

FIG. 10. As in Fig. 9, but instead for the MIB.

2-yr scale, we notice a clustering of high variability around 1800 that is preceded by a period of less variability. The cold winters of the early 1940s are also obvious in a series of large-amplitude events. In the $\tilde{D}_{4}$ plot there is a resemblance between the sixteenth, seventeenth, and twentieth centuries in terms of their decadal variability, with suppressed variability evident in the eighteenth and nineteenth centuries. Looking at the smoothed $\tilde{S}_{5}$ series we recognize the same pattern as in the temperature record, with milder winters occurring both in the early eighteenth and in the twentieth centuries.

\section{Discussion of atmospheric circulation and Baltic winter temperatures}

In the past century a marked increase of temperature of more than $0.7^{\circ} \mathrm{C}$ as well as shorter ice seasons have been seen in the region. These trends are statistically significant but they have not been shown to lie outside the range of natural variability (The BACC Author Team 2006). Based on the ice and air temperature time series we have identified important climate periods for the greater Baltic region over the past 300-500 yr. We now put these events into perspective, by compar- 


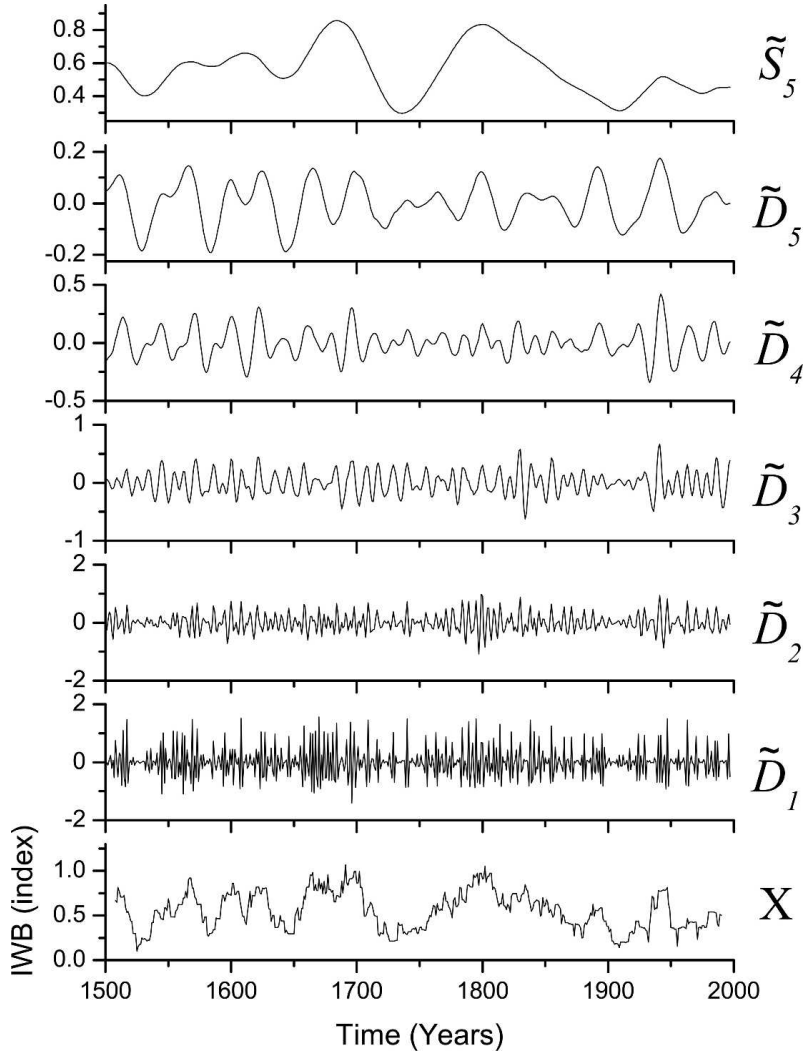

FIG. 11. As in Fig. 9, but instead for the IWB.

ing the periods identified in the MP analysis (see Table 2) with the Baltic Sea atmospheric winter circulation indices and the Baltic Sea winter air temperature (Fig. 12).

Circulation and temperature analyses extending back $500 \mathrm{yr}$ are rare, and most reconstructions focus on global or hemispheric means that do not provide information about regional-scale variations. Over this period Europe and the whole Northern Hemisphere experienced complex climatic change forcing the system into different modes (Lamb 1995; Luterbacher et al. 2002, 2004; Jacobeit et al. 2003; Xoplaki et al. 2005). Up to $95 \%$ of the variability in the general atmospheric circulation pattern over Northern Europe over the last $500 \mathrm{yr}$ can be explained by the first three spatial EOF components (Luterbacher et al. 2002); however, time evolution is a more complex situation. The compilation of gridded SLP datasets over Europe (e.g., Jones et al. 1999; Luterbacher et al. 2002) has made it possible to reconstruct circulation types from pressure patterns over specific regions, which potentially produce more accurate results than large-scale indices (e.g., Jacobeit et al. 2001, 2003). In general, the European climate is more complex than can be captured by a simple circulation index such as the NAO (Jacobeit et al. 2001,
2003; Slonosky and Yiou 2002). As shown by Jacobeit et al. (2001, 2003) and Slonosky and Yiou (2002), the European climate could be divided into different regions, all of which display unique behavior under the same type of large-scale forcing.

\section{a. Climate characteristics of MP1 (1522-36)}

The sixteenth century began with a mild period, which from the MRA (Fig. 11) also was shown to be a period with low interannual and biannual variability. Baltic Sea mean winter temperatures, calculated from the Luterbacher et al. (2004) data, varied from $-5^{\circ}$ to $-2^{\circ} \mathrm{C}$ at this time, and there was a stretch of mild winters unmatched in length until the early eighteenth century (Fig. 12, top panel). MP1 was preceded by increased westerly winds and decreased high-pressure activity (second and bottom panels, respectively, of Fig. 12). During MP1, however, westerly winds decreased in favor of southerly winds, while the strength of circulation remained constant (Fig. 12 bottom three panels). A possible explanation could be a more southerly Icelandic low causing the storm tracks to follow a more southwesterly path. The SLP charts (Luterbacher et al. 2002) especially show this feature during the years 1522, 1527, 1533, and 1536 (not shown). The Tallinn temperature series also shows mild temperatures during this time (Fig. 2h; Table 2), compared to the following century. A period with a marked decrease of the southerly meridional wind component connects MP1 with MP2 (Fig. 12, third panel).

\section{b. Climate characteristics of MP2 (1562-76)}

The MRA (Fig. 11) in MP2 (a cool phase) shows both large interannual and biannual variability. Seasonal mean winter temperatures, calculated from the Luterbacher et al. (2004) data, were estimated to be as low as $-9^{\circ} \mathrm{C}$ (Fig. 12, top panel). Southerly winds slightly increased, while both westerly winds and rotational flow were weak (Fig. 12, bottom three panels). The severe winter of 1537 is discussed in Luterbacher et al. (2002). MP2 is not obvious in the Tallinn temperature record (Fig. 2h; Table 2), which could be explained by the development of a persistent, blocking, cold high over central Europe, which reached unusually far westward [in analogy with the 1740 situation described by Moberg and Bergström (1997) and Luterbacher et al. (2002)]. This situation suggests a temperature anomaly gradient from northern to central and western Europe (Moberg and Bergström 1997). The winters of 15661568 and 1575 are the mildest winters that occur in the Tallinn record during MP2 and are responsible of the mild mean temperature for this period. SLP charts in- 


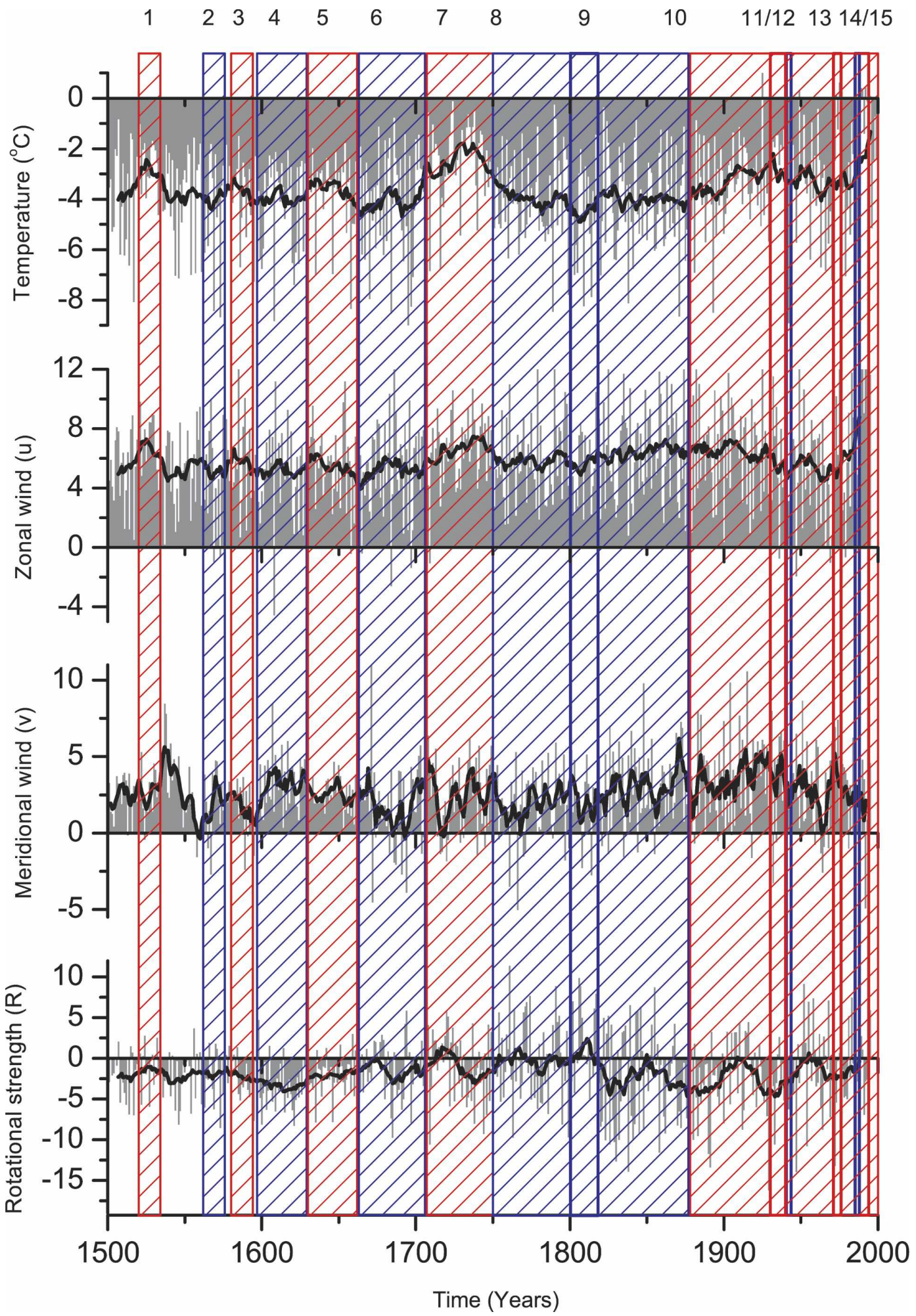

FIG. 12. The gray color shows seasonal winter data from the two gridded datasets (Table 1, columns i and j): (top to bottom) Baltic Sea mean winter air temperature, zonal wind component (westerly winds when positive and easterly winds when negative), meridional wind component (southerly winds when positive and northerly winds when negative), and rotational flows (cyclonic circulation when positive and anticyclonic when negative). Black line in all panels is a 15-yr running mean. Blue and red fields covers time periods classified by MP as mild and cold, respectively; the number above each field corresponds to the number in Table 2. 
dicate a tendency for higher pressure over central Europe during these years (not shown).This cold MP2 shifted rapidly toward a milder MP3.

\section{c. Climate characteristics of MP3 (1577-91)}

The MRA (Fig. 11) indicates low interannual variability during the mild MP3, as was also the case during the mild MP1. During MP3 mean winter temperatures, calculated from the Luterbacher et al. (2004) data, rose to $-1^{\circ} \mathrm{C}$ (Fig. 12, top panel). This period has increased westerly winds, decreased southerly flow, and a weak positive trend in high-pressure activity (Fig. 12, bottom three panels). The Tallinn temperature record (Fig. 2h) does not show significantly mild temperatures during MP3, having actually colder temperatures than during MP2, yet warmer than the succeeding MP4 (Table 2). In addition, the Riga record of ice breakup does not show a tendency for early ice breakup during MP3 (Fig. 2f; Table 2). The Tallinn and Riga records suggest an easterly cooling that could possibly be produced by a high-pressure center southeast of the Baltic Sea. This feature is evident in several of the years during MP3 from the Luterbacher et al. (2002) SLP data (not shown).

\section{d. Climate characteristics of MP4 (1597-1629)}

In late sixteenth and early seventeenth centuries a generally cold MP4 can be identified, which shows high variability on all scales from 1 to $8 \mathrm{yr}$ in the MRA (Fig. 11). Both southerly winds and anticyclonic circulation strengthened throughout this period. The lowest mean winter temperatures of this period, calculated from the Luterbacher et al. (2004) data, were reached in 1608 when $-9^{\circ} \mathrm{C}$ was documented (Fig. 12, top panel). However, around 1610, we can see that the period was interrupted by several mild years, which probably resulted from more frequent westerly winds (Fig. 12, second panel). Both the Tallinn temperature record and the Riga ice breakup points to severe winter conditions during this time (Table 2), although the Riga record is limited (Fig. 2f,h). A high-pressure center could presumably have been situated somewhere in the Baltic region during this time, thus blocking the westerlies from entering the region. This feature is indicated in the Luterbacher et al. (2002) SLP charts. MP4 gave way rapidly to a warmer period.

\section{e. Climate characteristics of MP5 (1630-62)}

Mild temperatures prevailed during MP5, and from the MRA (Fig. 11) a slight damping of the variability is apparent. Several winters in MP5 had mean tempera- tures, calculated from the Luterbacher et al. (2004) data, close to $-2^{\circ} \mathrm{C}$ until its end, when temperatures rapidly decreased (Fig. 12, top panel). A small negative trend near the end of MP5 is evident in both wind components, and at the same time the high-pressure circulation weakened (Fig. 12, bottom three panels). In the Tallinn temperatures (Fig. 2h) the first half of MP5 is generally cold while the second half is milder. This pattern could be explained by weakened high-pressure circulation.

\section{f. Climate characteristics of MP6 (1663-1706)}

In the winter of 1663 a cold MP6 started, which from the MRA (Fig. 11) begins with large interannual variability. MP6 is close to the time of the LMM (16751710), a period with low solar forcing. During the beginning of MP6 a strengthening of the westerly flow together with a weakening of the meridional component is observed (Fig. 12, second and third panel). This is followed by weakened westerlies and an unprecedented low level of the meridional wind component, giving rise to winters with northerly flow. At the beginning of MP6 the circulation strength was weak, but this was soon followed by years of temporarily increased negative rotation. Strong negative rotation indicates that winter high-pressure systems exerted a stronger influence over the region, implying colder temperatures, as can be seen in the top and bottom panels of Fig. 12. The coldest winter temperatures, calculated from the Luterbacher et al. (2004) data, of this period were achieved in 1684 and 1695, when average temperatures declined to $-10^{\circ} \mathrm{C}$. The circulation thus indicates a tendency toward colder winters at the beginning of the LMM with more frequent winter high-pressure systems.

But halfway through the LMM this tendency broke down, and the atmospheric circulation indicates warmer winters. Anticyclonic circulation strengthened up to 1685 , after which it weakened. This can be interpreted as indicating that in approximately 1685 , the LMM period gave way to a warming trend starting at very low values, which also is suggested from the SLP analysis in Luterbacher et al. (2001). These findings are similar to Fischer-Bruns et al. (2002) and Luterbacher et al. (2004), who found that NAO winter indices changed from negative to positive in 1684. Model-based simulations of the LMM by Shindell et al. (2001) showed that increasing solar irradiance at the end of the $\mathrm{MM}$ led to a positive NAO-AO, through complex interactions between the troposphere and the stratosphere. The recovery of the temperatures is, however, not necessarily synchronized with increased radiative forcing (Zorita et al. 2004). In the transition between 
MP5 and MP6 the Tallinn temperatures (Fig. 2h) experience a change from mild to colder conditions; however, during the later part of MP6 an upward trend can be seen. Data from the Torneå River (Fig. 2e) are also available for this period and reveal late dates for the ice breakup.

\section{g. Climate characteristics of MP7 (1707-50)}

A new mild event (MP7) is characterized by the MRA (Figs. 9-11) to be low in both interannual and biannual variability. Variability on the scale of $8 \mathrm{yr}$ is low for IWB (Fig. 11) during MP7 and stays this way until the end of MP8. This early eighteenth-century warm period saw unusual warm winters, several winters having mean temperatures, calculated from the Luterbacher et al. (2004) data, of approximately $-1^{\circ} \mathrm{C}$ (Fig. 12 , top panel). The warmest winter during this period was in 1724 , when the mean temperature was $0^{\circ} \mathrm{C}$. These mild winter temperatures were closely correlated with increased westerly winds (Fig. 12, second panel). While the first half of the period experienced both weakened southerly winds and positive (cyclonic) rotation, the latter half revealed enhanced southerly winds and a shift toward negative (anticyclonic) rotation (Fig. 12, third and bottom panel). Ice breakup in Lake Mälaren, as well as the Tallinn series (Figs. 2d,g,h), supports the mild conditions by showing really early breakup dates and mild temperatures. MP7 fits well with years $1710-48$ being reported by Nesje and Dahl (2003) as a period with rapid glacier advance in western Norway due to increased winter precipitation. This warming is also evident in mean winter temperatures for Europe (Luterbacher et al. 2004) and possibly caused by increased solar irradiance (Shindell et al. 2001). The characteristics of the period 1730-45 are described by Jones and Briffa (2006) as "rarely commented upon in proxy climatic reconstructions." Their study highlights the variability within the system by showing that the warmest documented decade, apart from the 1990s, was interrupted by the extraordinary cold winter of 1740 . With previously unpublished circulation charts developed by the late Hubert Lamb they show that the major features of the "normal" pressure maps (i.e., the Iceland low and the Azores high) were much weaker. The dominant feature was instead a continental or Scandinavian high, whose exact position determined the coldness of each winter.

\section{h. Climate characteristics of MP8 (1750-1877) and MP9 (1803-20)}

Starting in the middle of the eighteenth century the cold conditions of the long MP8 prevailed until the late nineteenth century (Fig. 12, top panel). The MRA (Figs. 9-11) shows that during MP8 there was high variability on both the interannual and biannual scales. In terms of atmospheric circulation a dramatic change is noticed in rotation halfway through MP8, when there was a shift during this period from cyclonic to anticyclonic circulation (Fig. 12, bottom panel). This change in rotation occurs at the end of MP9 and coincides with the Dalton Minima (1790-1840), a period with low solar forcing and increased volcanic activity with similarities to the LMM as noted in Zorita et al. (2004). The cold intensity during 1790-1820 is also discussed in van der Schrier and Barkmeijer (2005), who attribute it to advection of cold polar air and more variability in the position of the North Atlantic storm tracks. The end of MP8 in 1877 coincides with the end of the LIA in the Baltic Sea region (Omstedt and Chen 2001). The breakdown of the LIA was associated with some winters with strong westerly circulation and persistent high-pressure circulation (Fig. 12, second and bottom panel).

\section{i. Climate characteristics of MP10 (1877-2000), MP11 (1930-40), MP12 (1940-42), MP13 (1971-75), MP14 (1985-87), and MP15 (1988-93)}

The twentieth-century climate is classified on the basis of the MP analysis as mild, but MP10 also includes periods of major decadal variability. What is obvious from the MRA (Figs. 9-11) is that the transition between the nineteenth and twentieth centuries stands out as a period with low variability on all scales. There was a rapid decline in winter temperatures, calculated from the Luterbacher et al. (2004) data, during the first decades, followed by a weakening of the westerlies (Fig. 12, top and second panel). The last decades, however, experienced warmer winter temperatures together with increased westerlies. During this period the influence of southerly winds was stronger than during the preceding centuries (Fig. 12, third panel). The MRAs (Figs. 9-11) for MP11 have somewhat lower interannual and biannual variability. MP11 was a mild period, as can be seen in the individual years displayed as gray bars in the top panel of Fig. 12. In 1940 MP11 was interrupted by a cold MP12 including the winters from 1940 to 1942, which in northern Europe are well remembered as the cold winters of the Second World War. These winters were characterized by extremely low temperatures and very little influence from the westerlies (Fig. 12, top and second panel) and have been suggested to be linked to global El Niño effects (Brönnimann et al. 2004). MP13 saw mild winters and 
was characterized by both strong positive zonal and meridional flows (Fig. 12, top three panels). MP14 was the last cold period and was marked by weak zonal flow and temperatures well below average. Finally MP15 experienced strong westerlies and very warm temperatures (Fig. 12, top and second panel).

The coldest winter in the Baltic Sea in the last $500 \mathrm{yr}$ was that of 1695 , when the mean temperature calculated from the Luterbacher et al. (2004) data was $-10^{\circ} \mathrm{C}$; while the warmest winter was 1930 when the mean temperature was $0^{\circ} \mathrm{C}$. The sensitivity of sea ice to Baltic Sea winter temperatures has been investigated by Omstedt and Hansson (2006a,b). This study found that the Baltic Sea becomes almost completely ice covered or ice free at winter air temperatures of $-6^{\circ}$ and $+2^{\circ} \mathrm{C}$, respectively, which implies that the Baltic Sea never has been completely ice free during the last $500 \mathrm{yr}$.

\section{Conclusions}

This study has analyzed the last $500 \mathrm{yr}$ of Baltic Sea winter climate based on relatively well-documented time series, Uppsala temperatures, MIB, and IWB. Warm and cold periods of different durations were common features among different climatic parameters and locations. As expected, atmospheric circulation, particularly wind direction and rotation, explains much of the behavior of the temperature and ice time series.

The main conclusions are the following:

1) The joint use of MP and wavelets is a powerful method for characterizing the underlying structure of historical time series. MP reveals common patterns of an irregular nature, in most of the time series studied, for example, the early-eighteenthcentury warm period and the ending of the LIA. This result suggests both that the time series records were affected by common climatic forcing and that the method works well with different types of datasets.

2) The MRAs confirm the cold-warm periods selected in the MP analysis by revealing that a common feature for warm (cold) periods are low (high) variability at short time scales.

3) For the greater Baltic region there is considerable centennial-scale variability both in terms of mean conditions and the modulation of high-frequency (decadal) variability, as revealed by the MRA analysis.

4) The winter mean air temperature over the Baltic Sea has varied from $0^{\circ}$ to $-10^{\circ} \mathrm{C}$ over the previous
$500 \mathrm{yr}$, which implies that the Baltic Sea has been partly ice covered all winters for the last $500 \mathrm{yr}$.

Mild periods have reduced variability at short time scales and hence may be periods of increased climate stability. Cold regimes, on the other hand, display greater variability on interannual time scales. During the nineteenth century there was low variability on decadal time scales, especially in the period after the Dalton Minima. Because much climate data span only the twentieth century, our results suggest that its large decadal variability (warm in the 1930s and cold in the 1960s) gives only a limited and nonuniversal view of decadal shifts over a longer time record

The climate of the last $500 \mathrm{yr}$ has been characterized by centennial-scale variability and the modulation of interannual and decadal signals, often accompanied by rapid shifts. Multiannual events with years that are colder or warmer than average are revealed by the MP analysis and are present throughout the studied period. The 15 MP periods identified are consistent with the changes in temperature and circulation evident from the gridded temperature and pressure data (Luterbacher et al. 2002, 2004). There is little indication of major periodicities in the record; the Baltic climate is better characterized by discrete events. However, centennial-, interdecadal-, and decadal-scale events are prominent. Statistical methods by themselves are incomplete to identify physical mechanisms for the centennial variations. However, the apparent random initiation and different duration of events and the lack of "cycles" do support a major influence of intrinsic variability in atmospheric climate. The analysis of more comprehensive models might unveil the physical mechanisms operating in nature.

It is difficult to identify to what extent human activities have affected the Baltic climate over the region during the last $100 \mathrm{yr}$. The transition of the Baltic to a warm phase at the end of the nineteenth century appears to occur before the major influence of anthropogenic (greenhouse gas) forcing, based on analysis of the Intergovernmental Panel on Climate Change (IPCC) Fourth Assessment models (Wang et al. 2007). For the future we anticipate a weak warming trend, but the large variability shown over the last $500 \mathrm{yr}$ will be a major factor.

Acknowledgments. We thank Anna Eklund, Sveta Jevrejeva, Per Klingberg, Gerhard Koslowski, Juerg Luterbacher, Ari Seinä, and Andres Tarand for making the data available. Thanks are also due to Ulf Cederlöf for valuable lecture notes and discussions about vector fields, to Deliang Chen for commenting on the manu- 
script, and to Youmin Chen for calculating the circulation indices. We would also like to thank the anonymous reviewers for their constructive and valuable comments to the manuscript.

This work has been financed by Göteborg University and the Swedish Research Council under the G 600$335 / 2001$ contract and represents a contribution to the GEWEX-BALTEX program. This work has also been supported by the NOAA Arctic Research Program. NOAA/PMEL, contribution 2895.

\section{APPENDIX A}

\section{Decomposing a Linearized Vector Field into Five Basic Components}

The two-dimensional vector field $\mathbf{V}_{h}=(u \mathbf{i}, v \mathbf{j})$ is a function of time and horizontal coordinates, $\mathbf{r}=(x \mathbf{i}, y \mathbf{j})$. The vector field close to a point $\mathbf{r}_{0}=\left(\mathrm{x}_{0} \mathbf{i}, \mathrm{y}_{0} \mathbf{j}\right)$, can be expressed by means of the Taylor expansion where we only consider the linearized part, as follows:

$$
\mathbf{V}_{h}=\mathbf{V}_{0}+\mathbf{r} \cdot \boldsymbol{\nabla} \mathbf{V}_{h} .
$$

The velocity, $\mathbf{V}_{0}=\left(u_{0} \mathbf{i}, v_{0} \mathbf{j}\right)$, is the velocity at the origin position, $\mathbf{r}_{0}$, and $\boldsymbol{\nabla} \mathbf{V}_{h}$ is the velocity tensor. The velocity tensor and its transpose matrix $\boldsymbol{\nabla} \mathbf{V}_{h}^{\mathrm{T}}$, can be read in explicit form (e.g., Woan 2000) as follows:

$$
\boldsymbol{\nabla} \mathbf{V}_{h}=\left[\begin{array}{l}
\frac{\partial u}{\partial x} \frac{\partial v}{\partial x} \\
\frac{\partial u}{\partial y} \frac{\partial v}{\partial y}
\end{array}\right], \quad \nabla \mathbf{V}_{h}^{\mathrm{T}}=\left[\begin{array}{l}
\frac{\partial u}{\partial x} \frac{\partial u}{\partial y} \\
\frac{\partial v}{\partial x} \frac{\partial v}{\partial y}
\end{array}\right],
$$

with the introducing of this identity,

$$
\boldsymbol{\nabla} \mathbf{V}_{h}=\frac{1}{2}\left(\boldsymbol{\nabla} \mathbf{V}_{h}-\boldsymbol{\nabla} \mathbf{V}_{h}^{\mathrm{T}}\right)+\frac{1}{2}\left(\boldsymbol{\nabla} \mathbf{V}_{h}+\boldsymbol{\nabla} \mathbf{V}_{h}^{\mathrm{T}}\right) .
$$

The explicit form of Eq. (A1), after using Eq. (A3) and some rearrangements of the different components, reads

$$
\begin{aligned}
\mathbf{V}_{h}= & \mathbf{V}_{0}+\mathbf{r} \cdot \nabla \mathbf{V}_{h} \\
= & \left(u_{0} \mathbf{i}, v_{0} \mathbf{j}\right)+\frac{1}{2}[\zeta(-y \mathbf{i}+x \mathbf{j})+\varepsilon(x \mathbf{i}+y \mathbf{j}) \\
& \left.+\delta_{1}(y \mathbf{i}+x \mathbf{j})+\delta_{2}(x \mathbf{i}-y \mathbf{j})\right],
\end{aligned}
$$

where

$$
\begin{aligned}
\zeta & =\frac{\partial v}{\partial x}-\frac{\partial u}{\partial y}, \quad \varepsilon=\frac{\partial u}{\partial x}+\frac{\partial v}{\partial y}, \quad \delta_{1}=\frac{\partial u}{\partial y}+\frac{\partial v}{\partial x}, \\
\delta_{2} & =\frac{\partial u}{\partial x}-\frac{\partial v}{\partial y} .
\end{aligned}
$$

With new notations the horizontal velocity can be divided into five distinct components that read

$$
\begin{aligned}
\mathbf{V}_{h} & =\mathbf{V}_{\mathbf{0}}+\mathbf{R}+\mathbf{E}+\mathbf{D}_{1}+\mathbf{D}_{2} \\
\mathbf{V}_{0} & =\left(u_{0} \mathbf{i}, v_{0} \mathbf{j}\right) \\
\mathbf{R} & =1 / 2 \zeta(-y \mathbf{i}+x \mathbf{j}) \\
\mathbf{E} & =1 / 2 \boldsymbol{\varepsilon}(x \mathbf{i}+y \mathbf{j}) \\
\mathbf{D}_{1} & =1 / 2 \delta_{1}(y \mathbf{i}+x \mathbf{j}) \\
\mathbf{D}_{2} & =1 / 2 \delta_{2}(x \mathbf{i}-y \mathbf{j}) .
\end{aligned}
$$

The first term represents translation by zonal and meridional winds, $\left(\mathbf{V}_{0}\right)$; the second term represents rotation, $(\mathbf{R})$, either associated with positive values as cyclonic rotation or as negative values as anti cyclonic circulation. The third term, (E), represents expansion or divergence/convergence. The two deformation velocities fields represent the torque associated with the velocity field due to shear, $\left(\mathbf{D}_{1}\right)$, and normal deformation, $\left(\mathbf{D}_{2}\right)$, respectively.

\section{APPENDIX B}

\section{Matching Pursuit Algorithm}

Let $\mathbf{X}$ be an $N$-dimensional vector containing the elements of the time series $\left\{X_{t}: t=0, \ldots, N-1\right\}$. Let $\mathbf{D}$ be a set of $N$-dimensional vectors indexed over a finite set $\gamma$ :

$$
\mathbf{D} \equiv\left\{\mathbf{d}_{\gamma}: \gamma \in \Gamma\right\},
$$

where $\mathbf{D}$ is called a dictionary and $\mathbf{d}_{\gamma}=\left[d_{\gamma, 0}, d_{\gamma, 1}, \ldots\right.$, $\left.d_{\gamma, N-1}\right]^{\mathrm{T}}$ is called a dictionary element. Each dictionary element is normalized, such that

$$
\left\|\mathbf{d}_{\gamma}\right\|^{2}=\sum_{l=0}^{N-1} d_{\gamma, l}^{2}=1
$$

Matching pursuit is an algorithm that successively approximates $\mathbf{X}$ by means of orthogonal projections onto elements of $\mathbf{D}$. For any $\mathbf{d}_{\gamma_{0}} \in \mathbf{D}$, we project $\mathbf{X}$ onto this vector to form the approximation

$$
\mathbf{X}^{(1)} \equiv\left\langle\mathbf{X}, \mathbf{d}_{\gamma_{0}}\right\rangle \mathbf{d}_{\gamma_{0}} .
$$

We then construct the residual vector, $\mathbf{R}^{(1)} \equiv \mathbf{X}-\mathbf{X}^{(1)}$, so that

$$
\mathbf{X}=\mathbf{X}^{(1)}+\mathbf{R}^{(1)}=\left\langle\mathbf{X}, \mathbf{d}_{\gamma_{0}}\right\rangle \mathbf{d}_{\gamma_{0}}+\mathbf{R}^{(1)} .
$$

To minimize the energy in the residuals, $\left\|\mathbf{R}^{(1)}\right\|$, we choose $\gamma_{0} \in \Gamma$, such that

$$
\left|\left\langle\mathbf{X}, \mathbf{d}_{\gamma_{0}}\right\rangle\right|=\max _{\gamma \in \Gamma}\left|\left\langle\mathbf{X}, \mathbf{d}_{\gamma_{0}}\right\rangle\right| .
$$


We now want to decompose $\mathbf{R}^{(1)}$ by projecting it onto the vector of $\mathbf{D}$ that best matches $\mathbf{R}^{(1)}$ :

$$
\mathbf{R}^{(1)}=\left\langle\mathbf{R}^{(1)}, \mathbf{d}_{\gamma_{1}}\right\rangle \mathbf{d}_{\gamma_{1}}+\mathbf{R}^{(2)} .
$$

We can now write $\mathbf{X}=\mathbf{X}^{(2)}+\mathbf{R}^{(2)}$, letting $\mathbf{R}^{(0)}=\mathbf{X}$ :

$$
\mathbf{X}^{(2)}=\mathbf{X}^{(1)}+\left\langle\mathbf{R}^{(1)}, \mathbf{d}_{\gamma_{1}}\right\rangle \mathbf{d}_{\gamma_{1}}=\sum_{k=0}^{1}\left\langle\mathbf{R}^{(\mathrm{k})}, \mathbf{d}_{\gamma_{k}}\right\rangle \mathbf{d}_{\gamma_{k}} .
$$

Repeating this, after $m$ steps we obtain $\mathbf{X}=\mathbf{X}^{(m)}+$ $\mathbf{R}^{(m)}$, where

$$
\mathbf{X}^{(m)}=\sum_{n=0}^{m-1}\left\langle\mathbf{R}^{(n)}, \mathbf{d}_{\gamma_{n}}\right\rangle \mathbf{d}_{\gamma_{n}} .
$$

Energy is conserved because

$$
\begin{aligned}
\|\mathbf{X}\|^{2} & =\sum_{n=0}^{m-1}\left\|\left\langle\mathbf{R}^{(n)}, \mathbf{d}_{\gamma_{n}}\right\rangle \mathbf{d}_{\gamma_{n}}\right\|^{2}+\left\|\mathbf{R}^{(m)}\right\|^{2} \\
& =\sum_{n=0}^{m-1}\left|\left\langle\mathbf{R}^{(n)}, \mathbf{d}_{\gamma_{n}}\right\rangle\right|^{2}+\left\|\mathbf{R}^{(m)}\right\|^{2} .
\end{aligned}
$$

\section{APPENDIX C}

\section{Multiresolution Analysis}

Let $\mathbf{X}$ be an $N$-dimensional vector whose $t$ th element is $x_{t}$. For a given $J_{0}$, the MODWT transforms $\mathbf{X}$ into $J_{0}+1$ new vectors, each of dimension $N$. The first $J_{0}$ of these are denoted by $\tilde{\mathbf{W}}_{1}, \ldots, \tilde{\mathbf{W}}_{J_{0}}$ and constitute the MODWT wavelet coefficients associated with standardized scales of $\tau_{j}=2^{(j-1)}, j=1, \ldots, J_{0}$. The final vector is $\tilde{\mathbf{V}}_{J_{0}}$ and contains the MODWT scaling coefficients. Whereas the wavelet coefficients, $\tilde{\mathbf{W}}_{j}$, are proportional to changes in averages over a scale of $\tau_{j}$, these scaling coefficients are proportional to averages over a scale of $2 \tau_{J_{0}}$.

The MODWT is equivalent to the original time series in the sense that, given the MODWT coefficients, we can reconstruct $\mathbf{X}$. This leads to the following additive decomposition, which is known as a multiresolution analysis:

$$
\mathbf{X}=\sum_{j=1}^{J_{0}} \tilde{D}_{j}+\tilde{S}_{J_{0}}
$$

In the above, the "detail series," $\tilde{D}_{j}$, is an $N$ dimensional vector that depends solely on $\tilde{\mathbf{W}}_{j}$, and hence is constructed using just those wavelet coefficients that are associated with changes of averages on a scale of $\tau_{j}$. The final term, $\tilde{S}_{J_{0}}$, is called the "smooth series," and is based on the scaling coefficients, $\tilde{\mathbf{V}}_{J_{0}}$, and is associated with scales of $2 \tau_{J_{0}}$ and longer. Thus, an MRA is an additive decomposition that expresses a time series as the sum of several new series, each of which can be associated with variations on a particular scale.

In this study we have calculated the MRA from a MODWT using a D(4) (Daubechies) wavelet with reflection boundary conditions (Percival and Walden 2000).

\section{REFERENCES}

Alenius, P., and L. Makkonen, 1981: Variability of the annual maximum ice extent of the Baltic Sea. Arch. Meteor. Geophys. Bioklimatol., 29B, 393-398.

Appenzeller, C., T. F. Stocker, and M. Anklin, 1998: North Atlantic Oscillation dynamics recorded in Greenland ice cores. Science, 282, 446-449.

Bergström, H., and M. Ekman, 2002: A period of anomalous winter climate and the Scandinavian glacier maximum in the 1700s. Small Publications in Historical Geophysics, No. 11, $1-15$.

— series for Uppsala (1722-1998). Climatic Change, 53, 213252.

Brönnimann, S., J. Luterbacher, J. Staehelin, T. M. Svendby, G. Hansen, and T. Svenøe, 2004: Extreme climate of the global troposphere and stratosphere in 1940-42 related to El Niño. Nature, 431, 971-974.

Chen, D., 2000: A monthly circulation climatology for Sweden and its application to a winter temperature case study. Int. J. Climatol., 20, 1067-1076.

— Oscillation on the regional temperature variability in Sweden: Spatial and temporal variations. Tellus, 51A, 505-516.

_- and X. Li, 2004: Scale-dependent relationship between maximum ice extent in the Baltic Sea and atmospheric circulation. Global Planet. Change, 41, 275-283.

Eklund, A., 1999: Long observation series of ice freeze and breakup dates in Swedish lakes. 12th Northern Research Basins Symp. and Workshop, Reykjavik, Kirjubaejarklaustur and Hofn, Hornafjordur, Iceland, 35-43.

Fagan, B., 2000: The Little Ice Age: How Climate Made History, 1300-1850. Basic Books, 250 pp.

Fischer-Bruns, I., U. Cubasch, H. von Storch, E. Zorita, F. Gonzáles-Rouco, and J. Luterbacher, 2002: Modelling the late maunder minimum with a 3-dimensional OAGCM. CLIVAR Exchanges, No. 25, International CLIVAR Project Office, Southampton, United Kingdom, 59-61.

Grove, J. M., 2001: The initiation of the "Little Ice Age" in regions round the North Atlantic. Climatic Change, 48, 53-82.

Haapala, J., H. E. M. Meier, and J. Rinne, 2001: Numerical investigation of future ice conditions in the Baltic Sea. Ambio, 30, 237-244.

Hagen, E., and R. Feistel, 2005: Climatic turning points and regime shifts in the Baltic Sea region: The Baltic winter index (WIBIX) 1659-2002. Boreal Environ. Res., 10, 211-224.

Jacobeit, J., P. Jönsson, L. Bärring, C. Beck, and M. Ekström, 2001: Zonal indices for Europe 1780-1995 and running correlations with temperature. Climatic Change, 48, 219-241.

- , H. Wanner, J. Luterbacher, C. Beck, A. Philipp, and K. Sturm, 2003: Atmospheric circulation variability in the North-Atlantic-European area since the mid-seventeenth century. Climate Dyn., 20, 341-352.

Jevrejeva, S., 2001: Severity of winter seasons in the northern 
Baltic Sea between 1529 and 1990: Reconstruction and analysis. Climate Res., 17, 55-62.

_ , and J. C. Moore, 2001: Singular spectrum analysis of Baltic Sea ice conditions and large-scale atmospheric patterns since 1708. Geophys. Res. Lett., 28, 4503-4507.

,$- \ldots$, and A. Grinsted, 2003: Influence of the Arctic Oscillation and El Niño-Southern Oscillation (ENSO) on ice conditions in the Baltic Sea: The wavelet approach. J. Geophys. Res., 108, 4677, doi:10.1029/2003JD003417.

— , V. V. Drabkin, J. Kostjukov, A. A. Lebedev, M. Lepparanta, Y. U. Mironov, N. Schmelzer, and M. Sztobryn, 2004: Baltic Sea ice seasons in the twentieth century. Climate Res., 25, 217-227.

Jones, P. D., and K. R. Briffa, 2006: Unusual climate in northwest Europe during the period 1730 to 1745 based on instrumental and documentary data. Climatic Change, 79, 361-379.

_ , and Coauthors, 1999: Monthly mean pressure reconstructions for Europe for the 1780-1995 period. Int. J. Climatol., 19, 347-364.

Jurva, R., 1952: On the variations and changes of freezing in the Baltic during the last 120 years. Fennia, 75, 17-24.

Kajander, J., 1993: Methodological aspects on river cryophenology exemplified by a tricentennial breakup time series from Tornio. Geophysica, 29, 73-95.

Koslowski, G., and R. Glaser, 1995: Reconstruction of the ice winter severity since 1701 in the western Baltic. Climatic Change, 31, 79-98.

—, and - 1999: Variations in reconstructed ice winter severity in the western Baltic from 1501 to 1995, and their implications for the North Atlantic Oscillation. Climatic Change, 41, 175-191.

Lamb, H. H., 1995: Climate, History, and the Modern World. 2d ed. Routledge, 433 pp.

Leppäranta, M., and A. Seinä, 1985: Freezing, maximum annual ice thickness and break up of ice on the Finnish coast during 1830-1984. Geophysica, 21, 87-104.

Luterbacher, J., R. Rickli, E. Xoplaki, C. Tinguely, C. Beck, C. Pfister, and H. Wanner, 2001: The late Maunder Minimum (1675-1715) - A key period for studying decadal scale climatic change in Europe. Climatic Change, 49, 441-462.

— , and Coauthors, 2002: Reconstruction of sea level pressure fields over the eastern North Atlantic and Europe back to 1500. Climate Dyn., 18, 545-561.

—, D. Dietrich, E. Xoplaki, M. Grosjean, and H. Wanner, 2004: European seasonal and annual temperature variability, trends, and extremes since 1500. Science, 303, 1499-1503.

Mallat, S. G., and Z. F. Zhang, 1993: Matching pursuits with timefrequency dictionaries. IEEE Trans. Signal Process., 41, 3397-3415.

Moberg, A., and H. Bergström, 1997: Homogenization of Swedish temperature data. Part III: The long temperature records from Uppsala and Stockholm. Int. J. Climatol., 17, 667-699.

—, D. M. Sonechkin, K. Holmgren, N. M. Datsenko, and W. Karlen, 2005: Highly variable Northern Hemisphere temperatures reconstructed from low- and high-resolution proxy data. Nature, 433, 613-617.

Nesje, A., and S. O. Dahl, 2003: The "Little Ice Age"-Only temperature? Holocene, 13, 139-145.

Ogilvie, A. E. J., and T. Jónsson, 2001: "Little Ice Age" research: A perspective from Iceland. Climatic Change, 48, 9-52.

Omstedt, A., and D. Chen, 2001: Influence of atmospheric circulation on the maximum ice extent in the Baltic Sea. J. Geophys. Res., 106 (C3), 4493-4500.
— memory and response to changes in the water and heat balance components. Cont. Shelf Res., 26, 236-251.

— and _ 2006b: Erratum to: "The Baltic Sea ocean climate system memory and response to changes in the water and heat balance components." Cont. Shelf Res., 26, 1685-1687.

- C. Pettersen, J. Rodhe, and P. Winsor, 2004: Baltic Sea climate: $200 \mathrm{yr}$ of data on air temperature, sea level variation, ice cover, and atmospheric circulation. Climate Res., 25, 205 216.

Palosuo, E., 1953: A treatise on severe ice conditions in the Baltic Sea. Finnish Institute of Marine Research, No. 156, 130 pp.

Percival, D. B., and A. T. Walden, 2000: Wavelet Methods for Time Series Analysis. Cambridge University Press, 594 pp.

_ J. E. Overland, and H. O. Mofjeld, 2004: Modeling North Pacific climate time series. Time Series Analysis and Applications to Geophysical Systems, D. R. Brillinger et al., Eds., Springer, 151-167.

Seinä, A., and E. Palosuo, 1996: The classification of the maximum annual extent of ice cover in the Baltic Sea, 1720-1995. Meri, Report Series of the Finnishe Institute of Marine Research 27, 79-91.

Shindell, D. T., G. A. Schmidt, M. E. Mann, D. Rind, and A. Waple, 2001: Solar forcing of regional climate change during the Maunder Minimum. Science, 294, 2149-2152.

,-- R. L. Miller, and M. E. Mann, 2003: Volcanic and solar forcing of climate change during the preindustrial era. J. Climate, 16, 4094-4107.

Slonosky, V., and P. Yiou, 2002: Does the NAO index represent zonal flow? The influence of the NAO on North Atlantic surface temperature. Climate Dyn., 19, 17-30.

Speerschneider, C. I. H., 1915: About the ice conditions in the Danish Seas in order and recent times, the years 690-1860 (in Danish). Notes from the Danish Meteorological Institute 2, $141 \mathrm{pp}$.

Tarand, A. N., and P. Ø. Nordli, 2001: The Tallinn temperature series reconstructed back half a millennium by use of proxy data. Climatic Change, 48, 189-199.

The BACC Author Team, Eds., 2006: Assessment of climate change for the Baltic Sea Basin: The BACC project. International BALTEX Secretariat Publication 35, $26 \mathrm{pp}$.

Tinz, B., 1998: Sea ice winter severity in the German Baltic in a greenhouse experiment. Dtsche. Hydrogr. Z., 50, 33-45.

van der Schrier, G., and J. Barkmeijer, 2005: Bjerknes' hypothesis on the coldness during AD 1790-1820 revisited. Climate Dyn., 25, 537-553.

Wang, M., J. E. Overland, V. Kattsov, J. E. Walsh, X. Zhang, and T. Pavlova, 2007: Intrinsic versus forced variation in coupled climate model simulations over the Arctic during the twentieth century. J. Climate, 20, 1093-1107.

Woan, G., 2002: The Cambridge Handbook of Physics Formulas. Cambridge University Press, 217 pp.

Xoplaki, E., J. Luterbacher, H. Paeth, D. Dietrich, N. Steiner, M. Grosjean, and H. Wanner, 2005: European spring and autumn temperature variability and change of extremes over the last half millennium. Geophys. Res. Lett., 32, L15713, doi:10.1029/2005GL023424.

Zorita, E., H. von Storch, F. J. Gonzalez-Rouco, U. Cubasch, J. Luterbacher, S. Legutke, I. Fischer-Bruns, and U. Schlese, 2004: Climate evolution in the last five centuries simulated by an atmosphere-ocean model: Global temperatures, the North Atlantic Oscillation and the late Maunder Minimum. Meteor. Z., 13, 271-289. 